\title{
1 An analytical model for predicting specific cutting energy in whirling milling process
}

\section{ABSTRACT}

The specific cutting energy (SCE) of machining processes is a significant indicator for machining sustainability. However, the characteristics of SCE in whirling milling as a promising green process are unknown because of the special material removal mechanism of this process. This paper presents an analytical model for predicting SCE based on the material removal mechanism of whirling milling. The cutting parameters affecting the SCE characteristics are identified considering the un-deformed chip formation. An analytical model is developed as functions of the identified cutting parameters by calculating material removal volume and cutting forces. To validate the proposed model, the analytical model was applied in ball screw shaft whirling milling. The results indicate that the analytical model can be effectively used to predict the SCE with over 90\% accuracy. In addition, the effects of cutting parameters and material removal rate (MRR) on SCE were investigated and analyzed based on the proposed model, which can provide valuable information and guidance for the optimal selection of cutting parameters to minimize SCE and improve MRR. 
1 Nomenclature

\begin{tabular}{|c|c|}
\hline$A(\theta)$ & un-deformed chip cross-sectional area at rotation angle $\theta$ \\
\hline$E$ & cutting energy \\
\hline$E_{t}$ & rotation energy \\
\hline$E_{f}$ & axis feed energy \\
\hline$F_{t}(\theta), F_{r}(\theta), F_{a}(\theta)$ & tangential, radial, axial force component \\
\hline $\bar{F}_{t}, \bar{F}_{r}, \bar{F}_{a}$ & average tangential, radial, axial force component \\
\hline$K_{t s}, K_{r s}, K_{a s}$ & shearing force coefficients in tangential, radial, axial directions \\
\hline$K_{t p}, K_{r p}, K_{a p}$ & specific ploughing force coefficients in tangential, radial, axial directions \\
\hline$l(\theta)$ & edge contact length at rotation angle $\theta$ \\
\hline$M R R$ & material removal rate \\
\hline$n_{t}$ & rotating speed of whirling tool, i.e. cutting speed \\
\hline$n_{w}$ & workpiece speed \\
\hline$e$ & eccentricity between workpiece axis and whirling tool holder axis \\
\hline$p$ & lead of the screw \\
\hline$P_{\text {cutting }}$ & net cutting power \\
\hline$R$ & cutting tool nose rotation radius \\
\hline$d_{1}$ & screw thread outer diameter \\
\hline$d_{2}$ & screw thread root diameter \\
\hline$r_{t}$ & radius of cutting tool \\
\hline$S C E$ & specific cutting energy \\
\hline$t$ & cutting time of a chip formation of per cutting \\
\hline$V$ & material removal volume of per cutting \\
\hline$v_{f}$ & axis feed speed of cutting tools or whirling tool holder \\
\hline$v_{t}$ & tangential cutting velocity \\
\hline$Z$ & number of cutting tools \\
\hline$\alpha$ & mounting position angle \\
\hline$\beta$ & rotation angle of cutting tool between $(i-1)$-th cutting and $i$-th cutting \\
\hline$\theta$ & instantaneous cutting rotation angle \\
\hline
\end{tabular}




\section{Introduction}

$$
\text { Rapidly increasing global energy demand has caused a severe energy crisis and an increasingly }
$$
severe environmental impact. Manufacturing processes and activities contribute significantly to industrial energy consumption, which consume approximately $90 \%$ of total industrial energy (Salahi and Jafari, 2016). Machining processes used to remove material from workpieces are a major part of manufacturing industries, and are both energy wasting and inefficient ( $\mathrm{Li}$ et al., 2015). Cai et al. (2018) reported that the energy efficiency of machining processes is low, and is typically less than $30 \%$. In addition, machining processes using cutting machine tools consume more energy than other types of machining processes (such as lasers and welding) (Fraunhofer, 2012). Therefore, it is critical that manufacturing enterprises reduce energy consumption of machining processes, which will force process planners and operators to improve their understanding of energy conservation while carrying out production. Consequently, studies have been conducted to model machining energy consumption.

Whirling milling is a promising green process and one of the most significant machining processes, which is widely used to produce screw parts. It has numerous benefits, including high material removal efficiency and dry cutting (without cutting fluid). Screw parts, such as worm drives and ball screws, are key components in a large number of mechanical products, including machine tools, and mining and construction equipment. Because of the significant demand for screw parts and the unknown energy consumption characteristics of the whirling milling process, there is good potential for exploring energy savings in this process. Therefore, it is necessary to forecast and characterize the energy consumption of whirling milling, which would assist different levels (including machine operation, process design, and planning), to achieve energy saving for manufacturing sustainability and cleaner production.

Previous studies on energy consumption in machining processes reported that cutting energy consumed in actual material removal can range from $15 \%$ to $70 \%$ of total energy consumption (Dahmus and Gutowski, 2004), and plays an important role in energy efficiency (Wang et al., 2016) and the quality of new surfaces (Sealy et al., 2016a) in machined parts. Therefore, cutting energy for material removal should be considered in the energy modeling of machining processes. According to Bayoumi et al. (1994), specific cutting energy (SCE), which is defined as the energy consumed per unit material removal volume $\left(1 \mathrm{~cm}^{3}\right)$, is a key indicator of cutting energy. Pawade et al. (2009) reported that SCE (as an important parameter) has a significant impact on chip 
formation, cutting forces, tool wear, and machined surface integrity. To achieve high energy efficiency and high-quality surface generation of machining processes, it is essential to have a good understanding of the characteristics of SCE and its relationship with cutting parameters.

The SCE in machining processes has been investigated previously, such as by employing experimental data analysis methods to predict energy consumption and to improve the understanding of its characteristics with cutting parameters. An empirical model was developed by Nandy et al. (2009) to study the effects of cutting parameters on SCE employing response surface methodology based on plain-turning experiments under different lubricating environments. In addition, Sealy et al. (2016b) and Liu et al. (2016b) reported similar predictive models in hard milling using experimental data to quantify the relationship between SCE and cutting parameters. Paul et al. (2017) experimentally characterized the effects of cutting parameters and tool parameters on the back force and SCE in turning of AISI 1060 steel. Cui and Guo (2018) experimentally investigated the optimum cutting parameters in intermittent hard turning considering SCE, damage equivalent stress, surface roughness. A number of other researchers aimed to enhance the understanding of the variation in SCE in relation to un-deformed chip thickness through cutting experiments. For example, Balogun and Mativenga (2014) reported an empirical SCE model of end milling via the nonlinear regression of experimental data obtained by the Taguchi experiment, and then analyzed the relationship between SCE and un-deformed chip thickness. Balogun et al. (2015) reported a similar empirical model of end milling and turning process using experimental data to characterize SCE with un-deformed chip thickness. Gao et al. (2017) proposed a novel experimental method to clarify the relationship between SCE and cutting parameters, and presented a prediction model by using a fuzzy logic method based on experimental data to optimize cutting parameters in micro-milling. However, the above studies were primarily dependent on the design of experiment, accuracy of experimental data, and a large number of experiments. This has limited the wider application of the proposed research methodologies. However, analytical models of SCE are attracting increasingly attention.

In previous studies, the analytical models were typically developed as functions of cutting parameters, and could be used for energy prediction and to explore the relationship between energy and cutting parameters directly for traditional machining. The process parameters were employed to analyze the effects of feed rate, spindle speed, and width of flank wear on SCE in end milling (Bayoumi et al., 1994). Pawade et al. (2009) reported an analytical model in high-speed 
turning to predict SCE and to investigate the influence of cutting parameters. Recently, Liu et al. (2016a) proposed an analytical model via process parameters to predict SCE in slot milling, and the relationship between the SCE and surface roughness was then characterized under different cutting parameters. These analytical studies focused on traditional machining processes such as turning and milling.

In recent years, whirling milling, as a promising cutting machining process, has been widely used to produce precision transmission lead screw thread parts (such as worm drives and ball screw shafts) for modern advanced equipment using hard-to-machine materials. Whirling milling is a variant of milling, where the cutting tools are installed on the tool holder that encompasses the workpiece as shown in Fig. 1. It has numerous advantages, such as a high cutting rate of approximately nine times of traditional milling (Mohan and Shunmugam, 2007), high surface integrity of machined surfaces (Zanger et al., 2017) and low cost (Han and Liu, 2013). As opposed to the machining processes of typical turning or milling, the whirling milling process has a special material removal mechanism led from the combination of workpiece rotation, cutting tools rotation, cutting tools axial feed motion, the interrupted cut by multiple cutting tools, and time variant characteristics of un-deformed chips. The SCE characteristics are significantly different from those of conventional machining. In particular, as opposed to conventional machining processes, the relationship between SCE and cutting parameters in whirling milling has yet to be understood. In addition, the material removal rate (MRR), a key parameter related to cutting rate, plays a critical role in energy consumption. However, its relationship with SCE for the whirling milling process has been rarely studied.

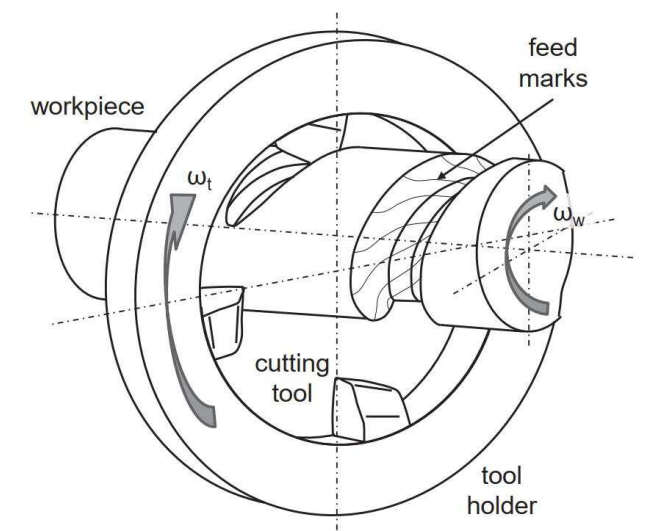

Fig. 1. A screw geometry by whirling milling (Zanger et al., 2017).

Therefore, the aim of this study is to develop an analytical model to predict the SCE of 
whirling milling, and to explore the coupling relationship between SCE, cutting parameters and MRR. The study is structured as follows. First, a description of the material removal mechanism of whirling milling is presented to explain how the cutting parameters affect SCE characteristics. This is followed by modeling the SCE of whirling milling based on the calculation of material removal volume and cutting force, which are functions of the identified cutting parameters. Experiments employing a ball screw shaft are then conducted to validate the proposed model. In addition, the effects of cutting parameters and MRR on SCE are then investigated and analyzed based on the proposed model. The results provide valuable information and guidance for optimal selection of cutting parameters to minimize SCEC and improve MRR.

\section{Specific cutting energy characteristics based on material removal mechanism of whirling milling}

Whirling milling has been widely used to product screw parts such as worm drives and ball screws, from hard-to-machine material for transmissions in the machinery equipment industry. It is a promising green machining process benefiting from high material removal efficiency, high surface quality, low cost and dry cutting (without cutting fluid).

The material removal mechanism of whirling milling for machining a ball screw shaft is shown in Fig. 2. In the whirling milling process, the screw is machined by a combination of workpiece rotation at a speed of $n_{w}$, the tool holder whirling at a rotational speed of $n_{t}$, and axial feed at a velocity of $v_{f}$. A number of cutting tools (the four cutting tools in Fig.2) are evenly clamped on the tool holder at a radius $R$, and the tool holder encompasses the workpiece with an offset of $e$. The tangential cutting velocity $v_{t}$ and axial feed velocity $v_{f}$ of the cutting tool are a result of the rotation of the tool holder and the axial feed, respectively. The workpiece material is successively removed by cutting tools with the rotating tool holder. When the cutting tool plunges in the workpiece material with velocities of $v_{t}$ and $v_{f}$, the cutting forces acting on the cutting tool in whirling milling are divided into three directions (see Fig. 2): the tangential force component $F_{t}(\theta)$, radial force component $F_{r}(\theta)$, and axial force component $F_{a}(\theta)$. The radial force component $F_{r}(\theta)$ consumes no energy during material removal in whirling milling because it is perpendicular to both axial feed velocity $v_{f}$ and tangential velocity $v_{t}$. Therefore, the energy for material removal during whirling milling is consumed by $F_{t}(\theta)$ parallel to $v_{t}$, and $F_{a}(\theta)$ parallel to $v_{f}$. 
As defined by Bayoumi et al. (1994), SCE is the energy used to remove a unit volume of material, and is defined as the ratio of cutting energy $E$ to material removal volume $V$. In this study, the cutting energy and material removal volume are investigated based on material removal mechanism to establish an analytical model for the modeling of the SCE in the whirling milling process. The cutting energy can be obtained based on cutting forces acting on the tool edge and speed of the cutting motion, as reported by Liu et al. (2015). The material removal volume can be obtained based on the cutting parameters.

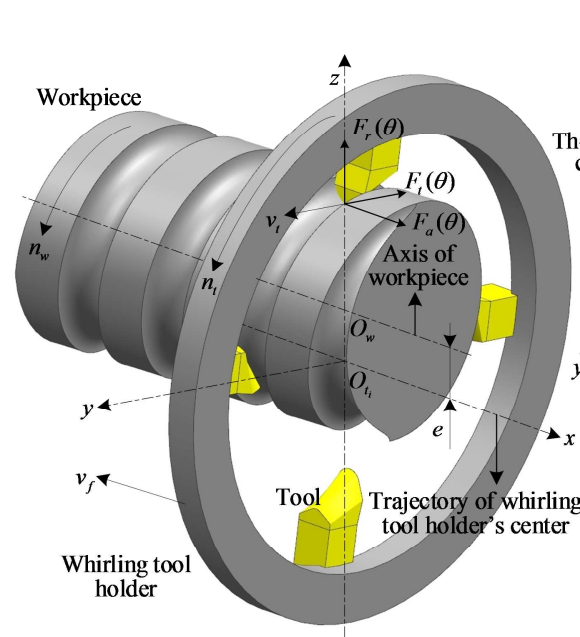

(a) Configuration

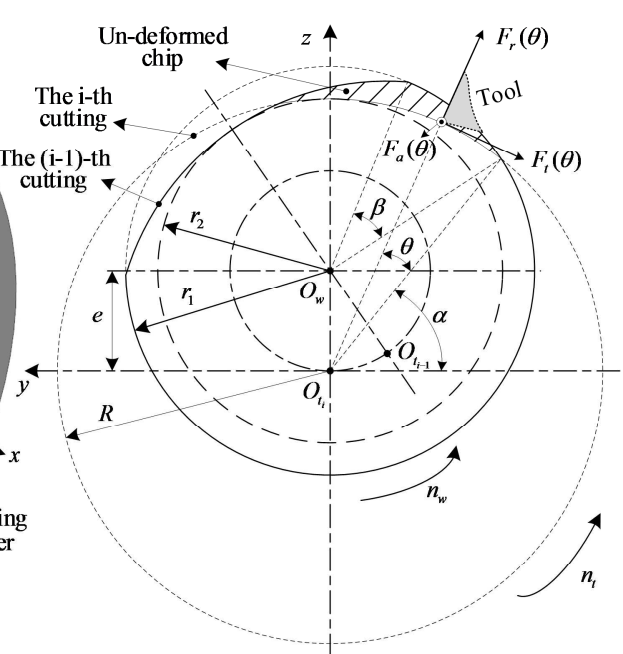

(b) Un-deformed chip formation

Fig. 2. Whirling milling mechanism for machining a ball screw shaft.

\subsection{Analysis of material removal mechanism and un-deformed formation}

In Fig. 2, the center of the workpiece is offset from the center of the whirling tool holder at a distance of $e$, which is the so-called the eccentricity. The whirling tool holder is rotated through the cutting tools nose with a rotation radius $R$. It can be seen in Fig. 2a that a number of cutting tools that were mounted on the tool holder could move in the radial direction of the tool holder. The material on the workpiece is removed by a combined movement of low-speed workpiece rotation $n_{w}$, high-speed cutting tools rotation $n_{t}$, and axial feed motion of the cutting tool $v_{f}$. Consequently, the cutting forces exerted on the cutting tool used to obtain the cutting energy of the whirling milling can be decomposed into a tangential force component $F_{t}(\theta)$, radial force component $F_{r}(\theta)$ and axial force component $F_{f}(\theta)$, where $\theta$ is the instantaneous cutting rotation angle. It has been shown that the cutting forces can be calculated using the un-deformed chip cross-sectional area $(a h(\theta))$ and edge contact length $(a)$ as follows (Altintas, 2012): 
$1\left\{\begin{array}{l}F_{t}(\theta)=K_{t c} a h(\theta)+K_{t e} a \\ F_{r}(\theta)=K_{r c} a h(\theta)+K_{r e} a \\ F_{a}(\theta)=K_{a c} a h(\theta)+K_{a e} a\end{array}\right.$

2 where $K_{t c}, K_{r c}$, and $K_{a c}\left(\mathrm{~N} / \mathrm{mm}^{2}\right)$ are the cutting force coefficients in the tangential, radial,

3 and axial direction, respectively; $K_{t e}, K_{r e}$, and $K_{a e}(\mathrm{~N} / \mathrm{mm})$ are the edge force coefficients in

4 the tangential, radial, and axial directions, respectively; the $\theta$ (rad) is the instantaneous rotation

5 angle of the cutting tool.

6 The un-deformed chip formation is directly related to the un-deformed chip cross-sectional area, edge contact length and material removal, which has a significant on SCE and cutting forces

8 (Pawade et al., 2009). In whirling milling, based on the rotational motions of the cutting tools and workpiece (as shown in Fig. 2), the un-deformed chip formation is described to identify the cutting parameters and to calculate the un-deformed chip cross-sectional area, edge contact length, material removal volume, and MRR. According to the un-deformed chip formation in Fig. 2b, a unit un-deformed chip is formed between the $\mathrm{i}$-th and (i-1)-th cutting. Therefore, the calculation of the material removal volume in whirling milling differs from that in typical machining processes because of the special un-deformed chip formation. However, the un-deformed chip cross-sectional area and edge contact length are time variant, with values from zero to maximum value and returning to zero during each chip formation. Therefore, the time variant characteristics of un-deformed chips have a significant influence on the estimation of cutting forces and material removal volume, and could further affect the cutting energy for SCE prediction.

\subsection{Cutting parameters identification}

For traditional machining, a number of parameters, such as depth of cut and cutting tool axial feed, have an influence on un-deformed chip formation. However, for thread whirling milling, the four key cutting parameters are workpiece speed, cutting speed, cutting tool nose rotation radius, and number of cutting tools because of the material removal mechanism (see Fig. 2). As reported by Serizawa et al. (2015), the depth of cut in whirling milling is controlled by the workpiece rotating in the eccentric whirling tool holder. According to the un-deformed chip formation details, as described in Section 3.1, the depth of cut is geometrically expressed as $|\mathrm{DE}|$ in the first cutting stage and $\left|D^{\prime} E\right|$ in the second cutting stage. Therefore, the depth of cut in whirling milling is a dependent parameter that can be calculated as a function of eccentricity $e$, mounting position 
angle $\alpha$, instantaneous rotation angle of cutting tool $\theta$, screw thread outer radius $r_{1}$, cutting tool nose rotation radius $R$, and rotation angle $\beta$ of the cutting tool between (i-1)-th cutting and i-th cutting. The mathematical formulations of $|\mathrm{DE}|$ and $\left|\mathrm{D}^{\prime} \mathrm{E}\right|$ will be presented in Section 3.1. In addition, the workpiece speed $n_{w}$ and the axial feed $v_{f}$ of the whirling tool holder are synchronized and coordinated to generate the lead of the thread. The axial feed $v_{f}$ of the cutting tool is also a dependent parameter, which can be calculated as $v_{f}=p n_{w}$, where $p$ is the lead of the screw, and $n_{w}$ is the workpiece speed. Therefore, the depth of cut and axial feed of cutting tools are closely related to the four cutting parameters because of the unique characteristics of the thread whirling milling process, are required for the analytical model.

In addition, the thread helix angle is set as the inclination angle of the whirling tool holder and can be neglected for precision transmission screw parts that have a small lead or pitch (i.e., small thread helix angle). For example, Serizawa et al. (2015) neglected the influence of thread helix angle to investigate the un-deformed chip formation of whirling milling for small pitch screws. In a previous study of the authors (Wang et al., 2014), the thread helix angle was also neglected because of the negligible influence caused by the small pitch on mechanistic modeling in whirling milling. Therefore, the thread helix angle was neglected when describing the un-deformed chip formation for the analytical modeling of SCE in whirling milling. The limitation is that the proposed analytical model in this study is suitable for whirling milling of small pitch screws. The study on whirling milling for large pitch screws will be a topic for future study by the authors.

Therefore, the four cutting parameters, namely workpiece speed $n_{w}(\mathrm{rpm})$, cutting speed $n_{t}$ (rpm), cutting tools nose rotation radius $R(\mathrm{~mm})$, and number of cutting tools $Z$ are identified to develop the analytical model for predicting SCE. Based on the above analysis, whirling milling is a complex machining process, and a number of assumptions are required in the development of the model. Following existing studies (i.e., Serizawa et al., 2015; Wang et al., 2014), the assumptions are described and added as follows: 1) The thread helix angle is neglected for the analytical modeling of SCE. The proposed analytical model is suitable for whirling milling of the small pitch screws, with a thread helix angle less than $3^{\circ} .2$ ) The workpiece is set as the reference and fixed without rotating; the whirling tool holder rotates around the center of the workpiece at a radius equal to the offset and travels along the workpiece axially with the axial feed. 


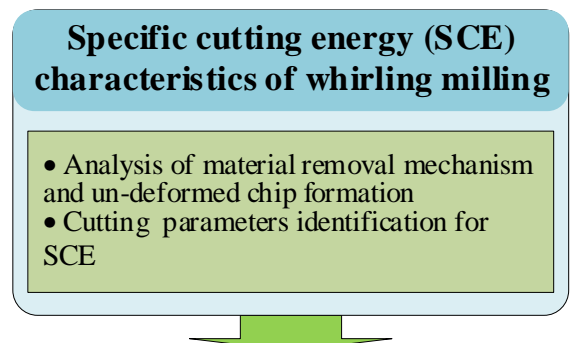

Analytical model of SCE

Material removal volume and MRR

- Determination of un-deformed chip cross section area $A(\theta)$ and edge contact length $l(\theta)$ - Calculation of material removal volume and MRR

\section{The cutting force model}

- Calculation of cutting force using $A(\theta), l(\theta)$ and force coefficients

- Identification of force coefficients through LSS regression method using the measured time domain force

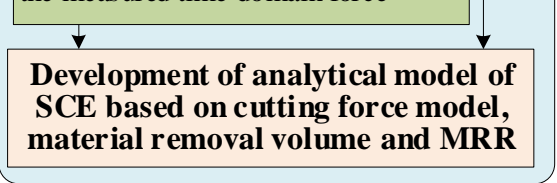

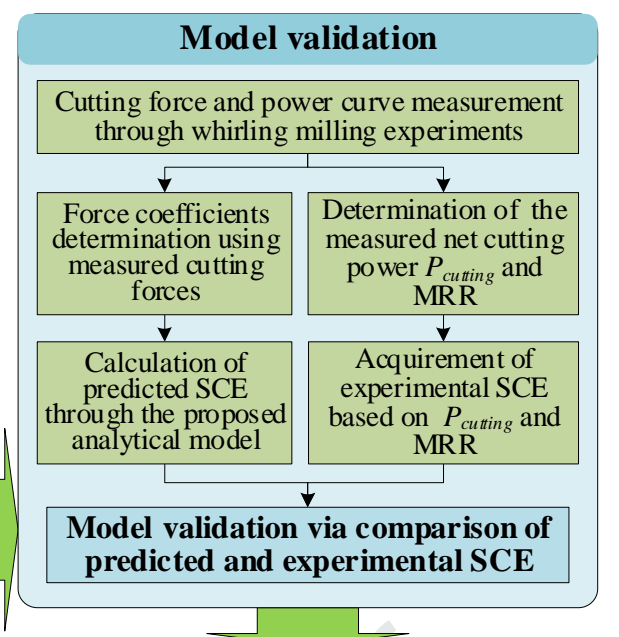

Results and discussion

Calculation of the SCE and MRR under different cutting parameter settings using the validated analytical model

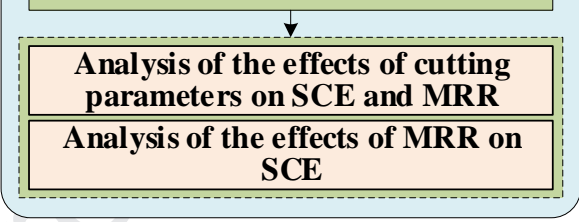

Fig. 3. Structure scheme of the research methodology used in this study.

\subsection{Research approach}

A structure scheme of the research methodology, as shown in Fig. 3, shows the approach followed in this study, including the modeling, parameter identification, model validation, and the performance analysis. Firstly, the material removal mechanism and un-deformed chip formation of whirling milling are analyzed to identify the cutting parameters for developing the SCE analytical model in this study. Based on the identified cutting parameters, the un-deformed chip cross-sectional area $A(\theta)$ and edge contact length $l(\theta)$ are determined to calculate the material removal volume and MRR. The cutting force model is then established using $A(\theta), l(\theta)$, and force coefficients, where the force coefficients can be calculated by the LSS regression method that will be described in detail in Section 3.2. Subsequently, the analytical model SCE is developed as functions of cutting parameters through the cutting force, material removal volume, and MRR.

In addition, the cutting force and power curve measurements were performed in whirling milling experiments. The force coefficients were determined through the LSS regression procedure using the measured time domain cutting forces. These obtained coefficients were further used to calculate the predicted SCE according to the proposed analytical model. In addition, the experimental SCE was obtained by MRR and the measured net cutting power $P_{\text {cutting. }}$. A 
comparison between the predicted and experimental SCE was then conducted to validate the proposed analytical SCE model. Finally, the SCE and MRR, under different cutting parameter settings, were calculated based on the validated analytical SCE model. Both the effects of cutting parameters on SCE and MRR and the effects of MRR on SCE were analyzed. The research results can provide valuable information and guidance for optimal selection of cutting parameters to reduce SCE as well as to improve MRR.

\section{Analytical SCE model of whirling milling}

In this section, the material removal volume and cutting forces are both calculated in details based on un-deformed chip formation. An analytical SCE model is established as functions of cutting parameters in the whirling milling process. In addition, the MRR is also calculated and its effects on SCE are analyzed in Section 5.

\subsection{Calculation of material removal volume and MRR}

For traditional milling, Sealy et al. (2016b) and Liu et al.(2016a) calculated the material removal volume and MRR using milling parameters, including axial depth of cut $a_{p}$, radial depth of cut $a_{e}$, feed per tooth $f_{z}$, and cutting speed $v$. Compared to traditional milling, it is difficult to directly calculate the material removal volume and MRR in the whirling milling process using cutting parameters because of the values of chip cross-sectional area and edge contact length changing from zero to a maximum value and returning to zero again, as discussed in Section 2. In this study, the material removal volume of whirling milling needs to be calculated by integrating the infinitesimal volume of un-deformed chip obtained using cutting parameters.

According to Fig. $2 b$, the un-deformed chip formation details of whirling milling are shown in Fig. 4. This figure shows that the cutting tools engaged in whirling milling remove materials because of the previous cutting (namely (n-1) th cutting) and the subsequent cutting (namely $n$th cutting). Therefore, polygon AFCB is the un-deformed chip. Arcs A-C, B-C, and A-B are the trajectories of the i-th cutting, trajectories of the (i-1)-th cutting, and workpiece outer circle, respectively.

The infinitesimal volume of the un-deformed chip, as shown in Fig. 4, can be expressed as $R A(\theta) d \theta$, where $R$ is the cutting tools nose rotation radius and $d \theta$ is the infinitesimal cutting tool rotation angle. In addition, to obtain the un-deformed chip-cross sectional area $A(\theta)$, the un-deformed chip formation is divided into two cutting stages due to the time variant 
characteristics of $A(\theta)$. As shown in Fig. 4, the cutting point moves from $\mathrm{A}$ to $\mathrm{F}$ in the 1st cutting stage; the cutting tool rotation angle is $\theta_{1}$; and $A(\theta)$ is the area of polygon GEHD based on cutting parameters. In the 2nd cutting stage, the cutting point moves from $\mathrm{F}$ to $\mathrm{C}$; the cutting tool rotation angle is $\theta_{2}$; and $A(\theta)$ is the area of polygon GEHD' based on cutting parameters. Finally, the material removal volume of whirling milling as well as the MRR can be calculated. In addition, the edge contact length $l(\theta)$ is also calculated as the length of $\operatorname{arc} \mathrm{G}-\mathrm{H}$, as shown in Fig. 4 , to estimate the cutting force in the following section.

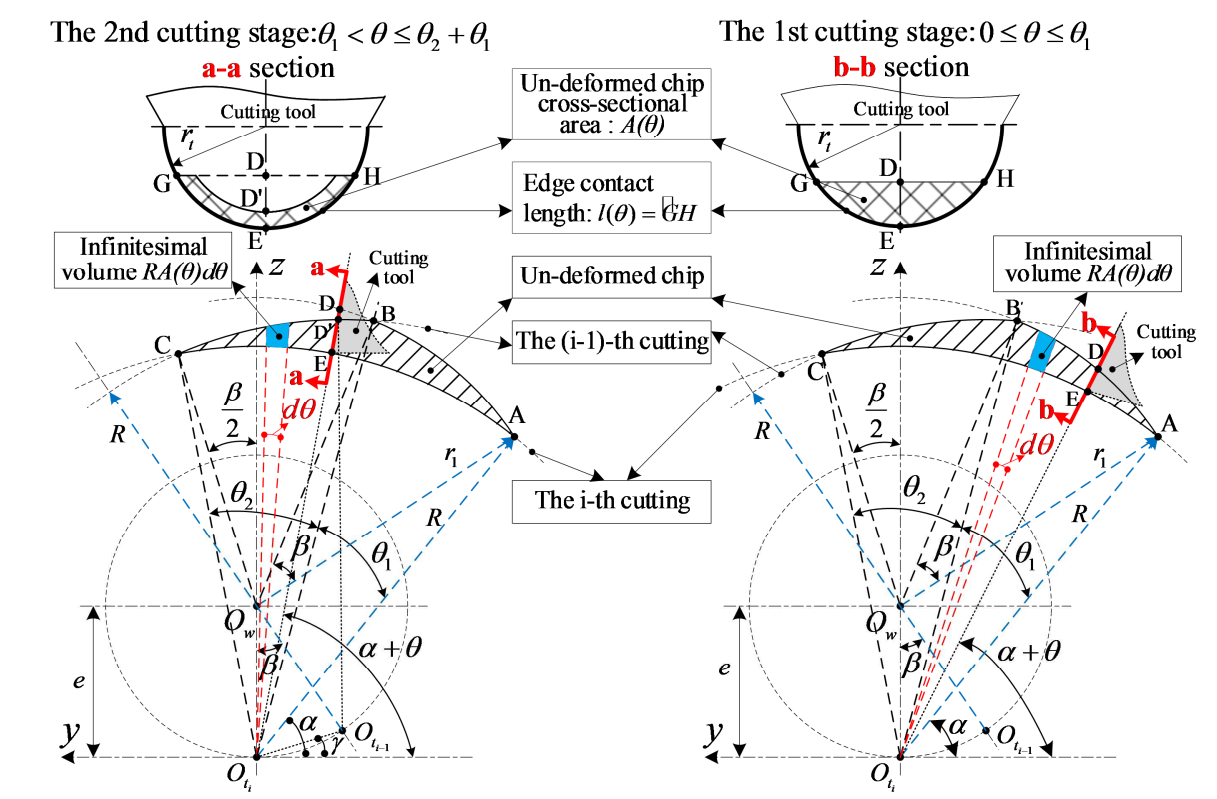

Fig. 4. Un-deformed chip formation details of whirling milling.

Based on un-deformed chip formation details, the $A(\theta)\left(\mathrm{mm}^{2}\right)$ and $l(\theta)(\mathrm{mm})$ are expressed as Eq. (2) and Eq. (3), respectively.

$$
\left\{\begin{aligned}
A(\theta)= & r_{t}^{2} \arccos \left(\frac{r_{t}-|D E|}{r_{t}}\right)-\left(r_{t}-|D E|\right) \sqrt{r_{t}^{2}-|D E|^{2}}, 0<\theta \leq \theta_{1} ; \\
A(\theta)= & r_{t}^{2} \arccos \left(\frac{r_{t}-|D E|}{r_{t}}\right)-\left(r_{t}-|D E|\right) \sqrt{r_{t}^{2}-|D E|^{2}} \\
& \quad-\left(r_{t}^{2} \arccos \left(\frac{r_{t}-\left|D D^{\prime}\right|}{r_{t}}\right)-\left(r_{t}-\left|D D^{\prime}\right|\right) \sqrt{r_{t}^{2}-\left|D D^{\prime}\right|^{2}}\right), \theta_{1}<\theta \leq \theta_{1}+\theta_{2} ;
\end{aligned}\right.
$$

where $r_{t}$ is the cutting tool radius; $\alpha$ is the mounting position angle; eccentricity $e$ is expressed as $e=R-r_{2} ; r_{1}$ and $r_{2}$ can be calculated as $r_{1}=d_{1} / 2$ and $r_{2}=d_{2} / 2$ respectively; $d_{1}$ and $d_{2}$ are the screw thread outer diameter and root diameter, respectively, both depending upon screw thread specifications; $|\mathrm{DE}|,\left|\mathrm{D}^{\prime} \mathrm{E}\right|$, and $\left|\mathrm{D}^{\prime} \mathrm{D}\right|$ can be geometrically given by Eqs. (2a), (2b), and (2c), respectively; and the cutting rotation angle $\theta_{1}$ in the 1st cutting stage and $\theta_{2}$ in the 2nd cutting stage as shown in Fig. 4 can be calculated by Eqs. (4) and (5), respectively. 
$1 \quad|D E|=\left|D O_{t_{i}}\right|-\left|E O_{t_{i}}\right|=e \sin (\alpha+\theta)+\sqrt{r_{1}^{2}-e^{2} \cos ^{2}(\alpha+\theta)}-R$

2 Where $\left|D O_{t_{i}}\right|=e \sin (\alpha+\theta)+\sqrt{r_{1}^{2}-e^{2} \cos ^{2}(\alpha+\theta)}, \quad \alpha=\frac{\pi}{2}-\angle O_{w} O_{t_{i}} A=\frac{\pi}{2}-\arccos \frac{R^{2}+e^{2}-r_{1}^{2}}{2 e R}$.

3 $\int\left|D^{\prime} E\right|=\left|D^{\prime} O_{t_{i}}\right|-\left|E O_{t_{i}}\right|=\left|D^{\prime} O_{t_{i}}\right|-R$

$=\left(+\sqrt{R^{2}-e^{2}(\sin \beta \sin (\alpha+\theta)-(1-\cos \beta) \cos (\alpha+\theta))^{2}}\right)-R$

4 where $\left|O_{t_{i}} O_{t_{i-1}}\right|=\sqrt{\left|O_{w} O_{t_{i}}\right|^{2}+\left|O_{w} O_{t_{t-1}}\right|^{2}-2\left|O_{w} O_{t_{i}}\right|\left|O_{w} O_{t_{i-1}}\right| \cos \beta}=e \sqrt{2-2 \cos \beta}, \beta=\frac{2 \pi n_{w}}{Z n_{t}}$,

$5 \quad\left|D^{\prime} O_{t_{i}}\right|^{2}+\left|O_{t_{i}} O_{t_{i-1}}\right|^{2}-2\left|D^{\prime} O_{t_{i}}\right|\left|O_{t_{i}} O_{t_{i-1}}\right| \cos \angle D^{\prime} O_{t_{i}} O_{t_{i-1}}=\left|D^{\prime} O_{t_{i-1}}\right|^{2}$,

$6 \cos \angle D^{\prime} O_{t_{i}} O_{t_{i-1}}=\cos (\alpha+\theta-\gamma)=\cos (\alpha+\theta) \cos \gamma+\sin (\alpha+\theta) \sin \gamma$,

$7 \quad \cos \gamma=\frac{\left|O_{w} O_{t_{i}}\right| \sin \beta}{\left|O_{t_{i}} O_{t_{i-1}}\right|}=\frac{\sin \beta}{\sqrt{2-2 \cos \beta}}$ and $\quad \sin \gamma=\frac{1-\cos \beta}{\sqrt{2-2 \cos \beta}} ;$ then,

$$
\left\{\begin{aligned}
\left|D^{\prime} O_{t_{i}}\right|= & \frac{\left.2\left|O_{t_{i}} O_{t_{i-1}}\right| \cos \angle D^{\prime} O_{t_{i}} O_{t_{i-1}}+\sqrt{\left(2\left|O_{t_{i}} O_{t_{i-1}}\right| \cos \angle D^{\prime} O_{t_{i}} O_{t_{i-1}}\right)^{2}-4\left(\left|O_{t_{i}} O_{t_{t-1}}\right|^{2}-\left|D^{\prime} O_{t_{t-1}}\right|^{2}\right.}\right)}{2} \\
= & e(\sin \beta \cos (\alpha+\theta)+(1-\cos \beta) \sin (\alpha+\theta) \\
& +\sqrt{R^{2}-e^{2}(\sin \beta \sin (\alpha+\theta)-(1-\cos \beta) \cos (\alpha+\theta))^{2}}
\end{aligned}\right.
$$

8

$$
\left\{\begin{aligned}
\left|D^{\prime} D\right|= & |D E|-\left|D^{\prime} E\right| \\
= & e \sin (\alpha+\theta)+\sqrt{r_{1}^{2}-e^{2} \cos ^{2}(\alpha+\theta)}-e(\sin \beta \cos (\alpha+\theta)+(1-\cos \beta) \sin (\alpha+\theta)) \\
& -\sqrt{R^{2}-e^{2}(\sin \beta \sin (\alpha+\theta)-(1-\cos \beta) \cos (\alpha+\theta))^{2}}
\end{aligned}\right.
$$

9

10

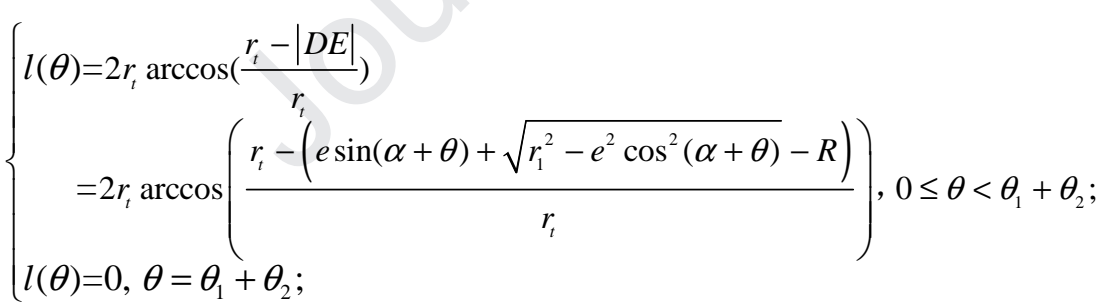

$11 \quad \theta_{1}=\angle O_{w} O_{t_{i}} A-\angle O_{w} O_{t_{i}} B=\arccos \left(\frac{R^{2}+e^{2}-r_{1}^{2}}{2 e r_{1}}\right)-\arccos \left(\frac{e^{2}+\left|O_{t_{i}} B\right|^{2}-r_{1}^{2}}{2 e\left|O_{t_{i}} B\right|}\right)$

12 where $\left|O_{t_{i}} B\right|=\sqrt{e^{2}+r_{1}^{2}-2 e r_{1} \cos \left(\beta+\angle O_{t_{i}} O_{w} A\right)}$ and $\angle O_{t_{i}} O_{w} A=\arccos \frac{r_{1}^{2}+e^{2}-R^{2}}{2 e r_{1}}$.

$13 \theta_{2}=\angle O_{w} O_{t_{i}} C+\angle O_{w} O_{t_{i}} B=\arccos \left(\frac{e^{2}+R^{2}-\left|O_{w} C\right|^{2}}{2 e R}\right)+\arccos \left(\frac{e^{2}+\left|O_{t_{i}} B\right|^{2}-r_{1}^{2}}{2 e\left|O_{t_{i}} B\right|}\right)$

14 where $\left|O_{w} C\right|^{2}+\left|O_{w} O_{t_{i}}\right|^{2}-2\left|O_{w} C\right|\left|O_{w} O_{t_{i}}\right| \cos \angle C O_{w} O_{t_{i}}=\left|C O_{t_{i}}\right|^{2} \quad, \quad \angle C O_{w} O_{t_{i}}=\pi-\frac{\beta}{2} \quad ; \quad$ then, 


$$
\left\{\begin{array}{rl}
\left|O_{w} C\right| & =\frac{2\left|O_{w} O_{t_{i}}\right| \cos \angle C O_{w} O_{t_{i}}+\sqrt{\left(2\left|O_{w} O_{t_{i}}\right| \cos \angle C O_{w} O_{t_{i}}\right)^{2}-4\left(\left|O_{w} O_{t_{i}}\right|^{2}-\left|C O_{t_{i}}\right|^{2}\right)}}{2} \\
& =\sqrt{R^{2}-e^{2} \sin ^{2} \frac{\beta}{2}}-e \cos \frac{\beta}{2}
\end{array} .\right.
$$
represented as:

$$
\left\{\begin{array}{l}
V=\int d V=\int_{0}^{\theta_{1}+\theta_{2}} A(\theta) R d \theta \\
=\int_{0}^{\theta_{1}} r_{t}^{2} \arccos \left(\frac{r_{-}-|D E|}{r_{t}}\right)-\left(r_{t}-|D E|\right) \sqrt{r_{t}^{2}-|D E|^{2}} R d \theta \\
\quad+\int_{\theta_{t}}^{\theta_{t}+\theta_{2}}\left(\begin{array}{c}
r_{t}^{2} \arccos \left(\frac{r_{t}-|D E|}{r_{t}}\right)-\left(r_{t}-|D E|\right) \sqrt{r_{t}^{2}-|D E|^{2}} \\
-\left(r_{t}^{2} \arccos \left(\frac{r_{t}-\left|D D^{\prime}\right|}{r_{t}}\right)-\left(r_{t}-\left|D D^{\prime}\right|\right) \sqrt{r_{t}^{2}-\left|D D^{\prime}\right|^{2}}\right)
\end{array}\right) R d \theta
\end{array}\right.
$$

$5 \quad M R R=\frac{V}{t}$

6 where $t(\mathrm{~s})$, is the cutting time of per cutting, can be expressed as $t=60 / Z n_{t} ; Z$ is the number of cutting tools; and $n_{t}(\mathrm{rpm})$ is the cutting speed.

\subsection{Cutting force model}

Studies have been conducted to simulate the whirling milling process. Mohan and Shunmugam (2007) simulated the tool profile of whirling milling for worm screws based on homogeneous coordinate transformation of discrete surface coordinates. However, because the simulation model used discrete surface coordinates, it is not suitable for investigating the un-deformed chip formation which has a significant effect on SCE and cutting forces. Lee et al. (2008) simulated the cutting forces of the whirling milling process based on the cutting volume and the measured SCE. In this model a constant SCE is assumed. This does not reflect the fact that the SCE is a variable due to the significant influence of cutting parameters on it. Moreover, a simulation model of cutting forces for whirling milling was proposed by Son et al. (2010) to compare the difference between cutting forces estimated by simulation software (such as DEFORM and ADAMS) and those measured in experiments. There was a significant discrepancy between these values. For example, the force simulations predicted $1472 \mathrm{~N}$ with ADAMS, and $325 \mathrm{~N}$ with DEFORM, whereas $858 \mathrm{~N}$ was measured experimentally. This discrepancy could be a result of the constant parameters (e.g., depth of cut) assumed in the simulation model. In addition, the number of cutting tools was not considered in the simulation model. For the whirling milling process, the depth of 
cut as a dependent parameter is variable and has a direct influence on the cutting cross-sectional area, as discussed above. Therefore, the cutting force model in this study is developed using the four cutting parameters (workpiece speed, cutting speed, cutting tool nose rotation radius, and number of cutting tools) and considering the variable depth of cut in the calculation of the cutting cross-sectional area.

In the whirling milling process, the cutting tools (cutting inserts) periodically cut into or out of the material in sequence because of the whirling milling material removal mechanism (Han and Liu, 2013; Serizawa et al., 2015). In addition, according to a previous study of the authors, only one of the cutting tools is used to cut during each cutting period (Wang et al., 2014). The cutting forces in whirling milling only act on the cutting tool being used to cut during its cutting period, and acts on every cutting tool periodically. As shown in Fig. 2, the cutting forces exerted on the cutting tool for whirling milling during each cutting period can be decomposed into a tangential force component $F_{t}(\theta)$, radial force component $F_{r}(\theta)$, and feed force component $F_{f}(\theta)$. Based on Eq. (1), it can be derived as follows:

$$
\left\{\begin{array}{l}
F_{t}(\theta)=K_{t s} \cdot A(\theta)+K_{t p} \cdot l(\theta) \\
F_{r}(\theta)=K_{r s} \cdot A(\theta)+K_{r p} \cdot l(\theta) \\
F_{a}(\theta)=K_{a s} \cdot A(\theta)+K_{a p} \cdot l(\theta)
\end{array}\right.
$$

where $K_{t s}, K_{r s}$, and $K_{a s}\left(\mathrm{~N} / \mathrm{mm}^{2}\right)$ are the specific shearing force coefficients in the tangential, radial, and axial directions, respectively; $K_{t p}, K_{r p}$, and $K_{a p}(\mathrm{~N} / \mathrm{mm})$ are the specific ploughing force coefficients in the tangential, radial, and axial directions, respectively; and $A(\theta)\left(\mathrm{mm}^{2}\right)$ and $l(\theta)(\mathrm{mm})$ are the un-deformed chip cross-sectional area and the edge contact length, respectively, at rotation angle $\theta$, as shown in Fig. 4.

The force coefficients are typically determined based on the measured time domain cutting forces data. The standard linear least squares (LLS) method has been demonstrated to be an appropriate method to obtain the cutting coefficients with experimental data points (Liu et al., 2015; 2016a). Therefore, according to Eq. (8), the tangential and axial force coefficients in this study can be calculated by using LLS based on $m$ selected points, as expressed in Eq. (9).

$$
\left\{\begin{array}{l}
{\left[\begin{array}{ll}
K_{t s} & K_{t p}
\end{array}\right]^{T}=\left(\boldsymbol{\Theta}^{T} \boldsymbol{\Theta}\right)^{-1} \boldsymbol{\Theta}^{T} \mathbf{F}_{t}} \\
{\left[\begin{array}{ll}
K_{r s} & K_{r p}
\end{array}\right]^{T}=\left(\boldsymbol{\Theta}^{T} \boldsymbol{\Theta}\right)^{-1} \boldsymbol{\Theta}^{T} \mathbf{F}_{r}} \\
{\left[\begin{array}{ll}
K_{a s} & K_{a p}
\end{array}\right]^{T}=\left(\boldsymbol{\Theta}^{T} \boldsymbol{\Theta}\right)^{-1} \boldsymbol{\Theta}^{T} \mathbf{F}_{a}}
\end{array}\right.
$$


$1 \quad \boldsymbol{\Theta}=\left[\begin{array}{cc}A\left(\theta_{1}\right) & l\left(\theta_{1}\right) \\ \vdots & \vdots \\ A\left(\theta_{i}\right) & l\left(\theta_{i}\right)\end{array}\right]$

$$
\left\{\begin{array}{l}
\bar{F}_{t}=\frac{1}{\theta_{1}+\theta_{2}} \int_{0}^{\theta_{1}+\theta_{2}} F_{t}(\theta) d \theta \\
\bar{F}_{r}=\frac{1}{\theta_{1}+\theta_{2}} \int_{0}^{\theta_{1}+\theta_{2}} F_{r}(\theta) d \theta \\
\bar{F}_{a}=\frac{1}{\theta_{1}+\theta_{2}} \int_{0}^{\theta_{1}+\theta_{2}} F_{a}(\theta) d \theta
\end{array}\right.
$$

\subsection{Analytical model of SCE}

As discussed in Section 3.2, the cutting forces in whirling milling only act on the cutting tool being used to cut during each cutting period, which means the cutting energy $E$ is consumed by only one cutting tool during each cutting period. The total cutting energy $E_{\text {total }}$ consumed during the total cutting time $t_{\text {total }}$ can then be calculated as $E_{\text {total }}=Z n_{t} t_{\text {total }} E$ where $Z, n_{t}$, and $E$ are the number of cutting tools, the cutting speed, and the cutting energy contributed by one cutting tool, respectively. The total material removal volume $V_{\text {total }}$ can be determined as $V_{\text {total }}=Z n_{t} t_{\text {total }} V$, where 
$1 \quad V$ is the material removal volume by one cutting tool, as shown in Eq. (6). The SCE analytical

2 model can be developed as $S C E=E_{\text {total }} / V_{\text {tota }}=E / V$. The cutting energy $E$ can be calculated

3 based on the above cutting force model. As the radial force component $F_{r}(\theta)$ is perpendicular to

4 both the tangential cutting velocity $v_{t}$ in rotational motion and the axis feed speed $v_{f}$ in feed

5 motion, therefore, there is no energy consumed by $F_{r}(\theta)$. The tangential force component $F_{t}(\theta)$

6 and axial force component $F_{a}(\theta)$ are parallel to the tangential cutting velocity and axis feed

7 speed $v_{f}$, respectively. Therefore, the cutting energy $E$ (J) can be divided into tangential cutting

8 energy $E_{t}$ expended by $F_{t}(\theta)$, and axis feed energy $E_{f}$ expended by $F_{a}(\theta)$. From Eq. (8), the

9 cutting energy $E$ per cutting of whirling milling can be expressed as follows:

$10 E=E_{t}+E_{f}$

$11 E_{t}=\int_{0}^{\theta_{1}+\theta_{2}} F_{t}(\theta) R d \theta=\int_{0}^{\theta_{1}+\theta_{2}}\left(K_{t s} A(\theta)+K_{t p} l(\theta)\right) \frac{R}{1000} d \theta$

$\left\{\begin{aligned} E_{f} & =\int_{0}^{t} v_{f} F_{a}(\theta) d t \\ & =\int_{0}^{\theta_{1}+\theta_{2}} \frac{p n_{w}}{60000} F_{a}(\theta) \frac{d \theta}{2 \pi n_{t} / 60}=\int_{0}^{\theta_{1}+\theta_{2}} \frac{p n_{w}}{2000 \pi n_{t}}\left(K_{a s} A(\theta)+K_{a p} l(\theta)\right) d \theta\end{aligned}\right.$

where axis feed speed $v_{f}(\mathrm{~m} / \mathrm{s})$ can be expressed as $v_{f}=p n_{w} / 60000 ; n_{w}(\mathrm{rpm})$ and $n_{t}(\mathrm{rpm})$ are the workpiece speed and cutting speed, respectively; and $p(\mathrm{~mm})$ is the lead or pitch of the screw thread, depending on the specification. Based on Eqs. (6), (7) and (11-11b), and the definition of SCE $\left(\mathrm{J} / \mathrm{mm}^{3}\right)$ by Bayoumi et al. (1994), the analytical SCE model can be developed as follows:

$$
\begin{aligned}
S C E & =\frac{E}{V}=\frac{E_{t}+E_{f}}{V} \\
& =\frac{\int_{0}^{\theta_{1}+\theta_{2}}\left(K_{t s} A(\theta)+K_{t p} l(\theta)\right) \frac{R}{1000} d \theta+\int_{0}^{\theta_{1}+\theta_{2}} \frac{p n_{w}}{2000 \pi n_{t}}\left(K_{a s} A(\theta)+K_{a p} l(\theta)\right) d \theta}{V} \\
& =\frac{\left(\frac{K_{t s}}{1000}+\frac{p n_{w} K_{a s}}{2000 \pi R n_{t}}\right) \int_{0}^{\theta_{1}+\theta_{2}} A(\theta) R d \theta+\left(\frac{K_{t p}}{1000}+\frac{p n_{w} K_{a p}}{2000 \pi R n_{t}}\right) \int_{0}^{\theta_{1}+\theta_{2}} l(\theta) R d \theta}{V}
\end{aligned}
$$

The SCE $\left(\mathrm{J} / \mathrm{mm}^{3}\right)$ is then calculated as Eq. (12b) by substituting the material removal volume (Eq. (6)) and MRR (Eq. (7)).

$$
\left\{\begin{aligned}
S C E & =\frac{K_{t s}}{1000}+\frac{p n_{w} K_{a s}}{2000 \pi R n_{t}}+\left(K_{t p}+\frac{p n_{w} K_{a p}}{2000 \pi R n_{t}}\right) \frac{R \int_{0}^{\theta_{t}+\theta_{s}} l(\theta) d \theta}{M R R t} \\
& =\frac{K_{t s}}{1000}+\frac{p n_{w} K_{a s}}{2000 \pi R n_{t}}+\left(\frac{K_{t p}}{1000}+\frac{p n_{w} K_{a p}}{2000 \pi R n_{t}}\right) \frac{Z n_{t} R \int_{0}^{\theta_{t}} l \theta_{2}}{60 M R R}(\theta) d \theta
\end{aligned}\right.
$$

\section{Experimental work}


This section presents the detailed experimental design and setup used to determine the cutting force coefficients and net cutting power. The experimental SCE was obtained as the ratio of net

3 cutting power decomposed from the measured power curve to MRR. Accordingly, the results of predicted and experimental SCE were compared to validate the proposed analytical model.

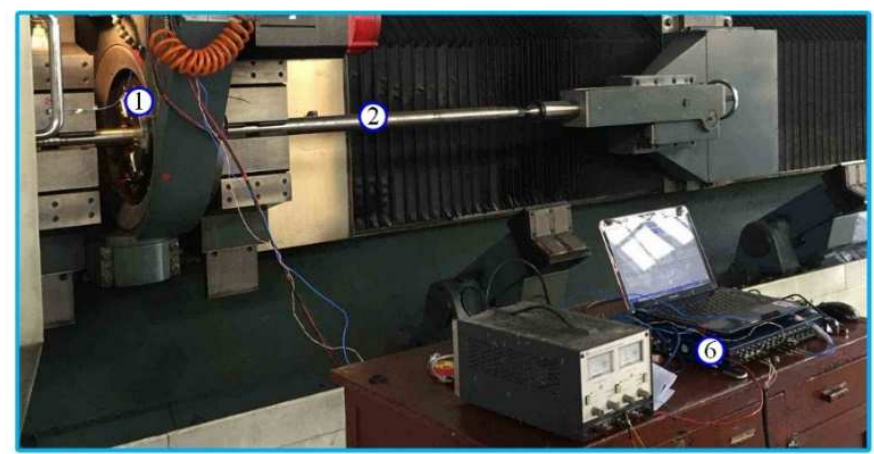

(a) Experimental setup using CNC whirling milling machine (HJ092 × 80)

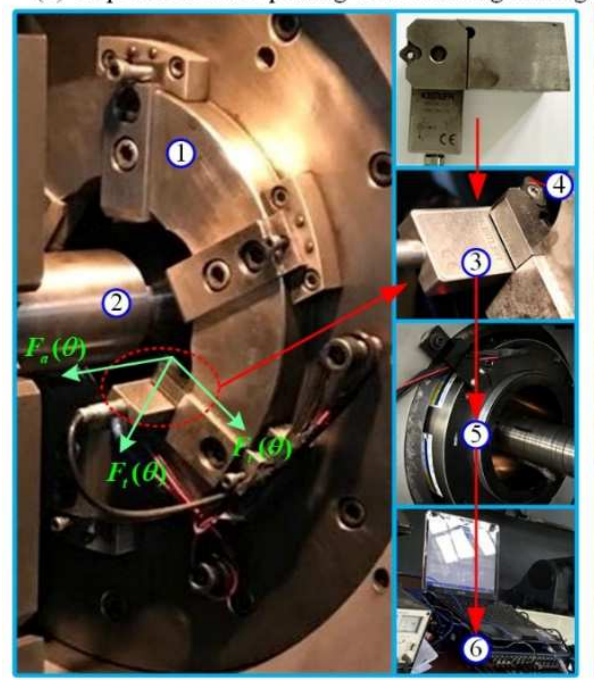

(b) Measurement of cutting forces

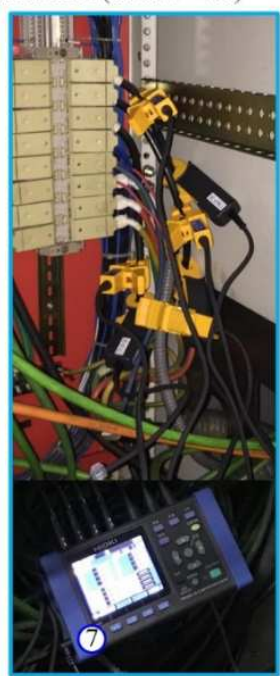

(c) Measurement of power

Fig. 5. Experimental data measurement configuration. (1) Whirling tool holder; (2) Workpiece; (3) Piezoelectric force sensor (Kistler 9602A); (4) Cutting tool; (5) Slip ring; (6) Data acquisition equipment (PROSIG P8020); (7) HIOKI PW3365-30 clamp-on power quality analyzer meter.

\subsection{Experimental design and setup}

To validate the proposed analytical SCE, a series of experiments were conducted by whirling milling a ball screw shaft on a CNC whirling machine $(\mathrm{HJ} 092 \times 80)$ which was developed by Hanjiang Machine Tool Co., Ltd, China. The PCBN cutting tools $\left(r_{t}=3.304 \mathrm{~mm}\right)$ were used. The test workpiece material selected for the experiments under dry cutting condition was GCr15 bearing steel (AISI 52100, approximately $62 \mathrm{HRC}$ after heat treatment), which is one of the most common materials used for transmission parts. Its chemical composition, the properties of the workpiece material, and dimension parameters of the workpiece are presented in Table 1 . The test sample was a cylindrical bar (after heat treatment) with dimensions of $\varnothing 78.5 \mathrm{~mm} \times 2000 \mathrm{~mm}$. 
2 Chemical composition and properties of workpiece material and dimension parameters of workpiece.

\begin{tabular}{lll}
\hline \multirow{2}{*}{ Chemical composition (wt\%) } & $\begin{array}{l}\mathrm{C}(0.98) ; \mathrm{Cr}(1.5) ; \mathrm{Mn}(0.35) ; \mathrm{Si}(0.21) ; \mathrm{S}(0.02) ; \mathrm{P} \\
(0.021) ; \mathrm{Fe}(\text { Balance })\end{array}$ \\
\hline & Density $\left(\mathrm{kg} / \mathrm{m}^{3}\right)$ & 7810 \\
& Young's modulus $(\mathrm{GPa})$ & 201 \\
& Hardness (HRC) & 62 \\
Properties & Poisson's ratio & 0.277 \\
& Thermal conductivity (W/ & 46.6 \\
& $(\mathrm{~m} \mathrm{~K}))$ & 78.5 \\
\hline \multirow{3}{*}{ Dimension parameters of } & Outer diameter $d_{1}(\mathrm{~mm})$ & 73.8 \\
workpiece & Root diameter $d_{2}(\mathrm{~mm})$ & 10 \\
\hline
\end{tabular}

The experimental data measurement configuration is shown in Fig. 5. A piezoelectric force sensor (Kistler 9602A), with integrated charge amplifier electronics was installed on the tool apron and rotated with the cutting tool to collect the cutting forces. Because of the rotation of force sensor with the cutting tool, a slip ring was used to connect the force sensor and the data acquisition equipment. A data acquisition unit (PROSIG P8020, Prosig Ltd, USA) was used to collect the cutting force data. The power curve of the $\mathrm{CNC}$ whirling machine in whirling milling was measured with a clamp-on power quality analyzer meter produced (HIOKI PW3365-30, HIOKI Company).

As analyzed in Section 2, the cutting parameters are cutting speed $n_{t}$, workpiece speed $n_{w}$, number of cutting tools $Z$, and tool nose rotation radius $R$. In addition, the values of these parameters were selected according to the forming requirements of the screw surfaces and capacity of the whirling machine tools in accordance with manufacturer recommendations. The experiments were performed with the four parameters at three levels, as presented in Table 2 . There was a total of 81 parameter settings without any design of experiment (DOE) method. Hence, the Taguchi method was chosen in the experiment design due to its widely accepted benefits (Camposeco-Negrete, 2013). The combinations of cutting parameter in experiments can be determined using the Taguchi method, as shown in Table 3. Each set of cutting parameters was tested three times so that to reduce random experimental errors. In addition, the bandwidths of the cutting force measurement were measured, by the institute of the authors ( $\mathrm{Ni}$ and $\mathrm{Li}, 2015$ ), to be approximately $1080 \mathrm{~Hz}, 942 \mathrm{~Hz}$, and $1200 \mathrm{~Hz}$ for the tangential, radial, and axial forces, respectively. The cutting forces in the experiments could be effectively measured when the bandwidth was sufficiently large compared to the maximum tooth passing frequency, i.e., $200 \mathrm{~Hz}$ $\left(n_{t}=1500 \mathrm{rpm}\right.$ and $\left.Z=8\right)$. 
Table 2

3 Levels of cutting parameters used in whirling milling experiments.

\begin{tabular}{ll}
\hline Parameters & Levels \\
\hline Cutting speed $n_{t}(\mathrm{rpm})$ & $500,1000,1500$ \\
Workpiece speed $n_{w}(\mathrm{rpm})$ & $2,5,8$ \\
Number of cutting tools $Z$ & $4,6,8$ \\
Cutting tool nose rotation radius $R(\mathrm{~mm})$ & $40,45,50$ \\
\hline
\end{tabular}

Table 3

5 Cutting parameters in experiments.

\begin{tabular}{|c|c|c|c|c|}
\hline $\begin{array}{l}\text { Test group } \\
\text { no. }\end{array}$ & $\begin{array}{l}\text { Cutting speed } n_{t} \\
(\mathrm{rpm})\end{array}$ & $\begin{array}{l}\text { Workpiece speed } n_{w} \\
(\mathrm{rpm})\end{array}$ & $\begin{array}{l}\text { Number of cutting } \\
\text { tools } Z\end{array}$ & $\begin{array}{l}\text { Cutting tool nose rotation } \\
\text { radius } R(\mathrm{~mm})\end{array}$ \\
\hline 1 & 500 & 2 & 4 & 40 \\
\hline 2 & 500 & 5 & 6 & 45 \\
\hline 3 & 500 & 8 & 8 & 50 \\
\hline 4 & 1000 & 2 & 6 & 50 \\
\hline 5 & 1000 & 5 & 8 & 40 \\
\hline 6 & 1000 & 8 & 4 & 45 \\
\hline 7 & 1500 & 2 & 8 & 45 \\
\hline 8 & 1500 & 5 & 4 & 50 \\
\hline 9 & 1500 & 8 & 6 & 40 \\
\hline
\end{tabular}

6

$7 \quad$ 4.2. Measurement and model validation

\section{$8 \quad$ 4.2.1. Predicted SCE}

The cutting force coefficients required in the analytical SCE model should be determined according to Eq. (12b) in Section 3.3. In the experiments, the forces under the same conditions in each cutting test were measured three times. Liu et al. (2015; 2016a) reported that the measured cutting force profiles under one test group 1 was used to calculate the force coefficients, and the measured profiles under the other test groups (2-9) were used to validate and adjust the obtained coefficients. Therefore, the $K_{t}$ and $K_{a}$ were obtained according to Eq. (9) in Section 3.2 by using 1000 measured experimental data points of $F_{t}(\theta)$ and $F_{a}(\theta)$, respectively, for test group 1 in Table 3. Based on the LLS, the obtained force coefficients were $K_{t s}=1040.54 \mathrm{~N} / \mathrm{mm}^{2}, K_{t p}=$ $2.47 \mathrm{~N} / \mathrm{mm}, \quad K_{a s}=300.85 \mathrm{~N} / \mathrm{mm}^{2}$ and $K_{a p}=2.00 \mathrm{~N} / \mathrm{mm}$. The confidence interval of the identified force coefficients was $95 \%$

To validate the effectiveness of the obtained cutting force coefficients, the predicted cutting 20 force profiles were compared to the measured profiles of $F_{t}(\theta)$ and $F_{a}(\theta)$ in test group 6, as 21 shown in Fig. 6. The rotation angles ( $\theta$ in Fig. 6) of the cutting tool positions were determined by using the cutting time $t(\mathrm{~s})$, i.e., $\theta=2 \pi n_{t} t / 60$, where $n_{t}$ is cutting speed (rpm). A good agreement 
was observed between the predicted cutting forces and the measured data, both in tendency and magnitude. In addition, using Eq. (10), the average predicted cutting forces were calculated to compared with the measured results under test group 2-9 (see Fig. 7), which could guarantee that the obtained coefficients could be appropriately used to predict cutting forces with a smaller than $9 \%$ of prediction error in whirling milling. The predicted SCE can be obtained according to Eq. (12b) based on the cutting parameters and obtained cutting force coefficients.

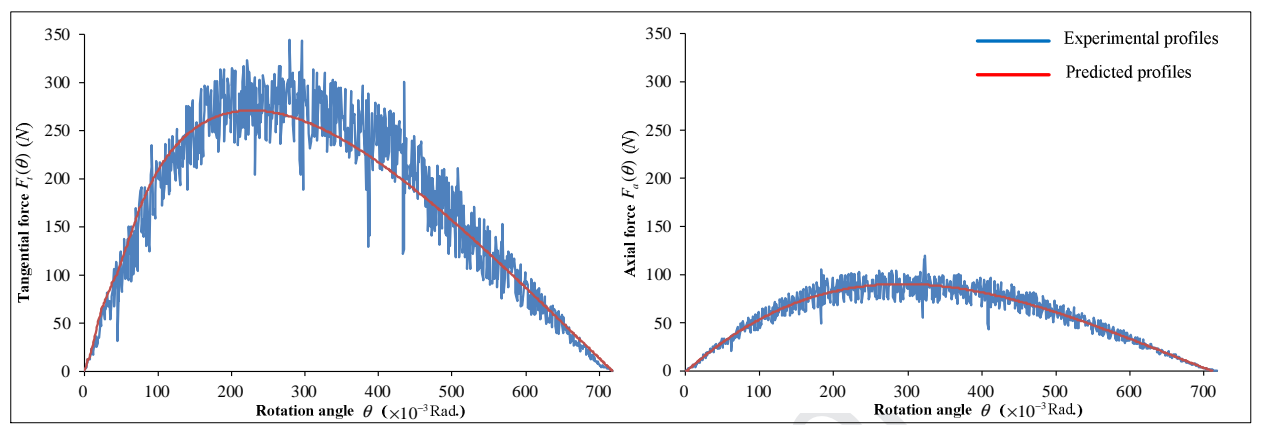

Fig. 6. Comparison between estimated and measured cutting force profiles of $F_{t}(\theta)$ and $F_{a}(\theta)$ in test group 6.

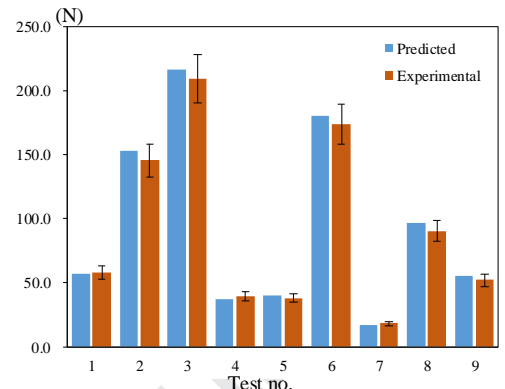

(a) Average tangential cutting force

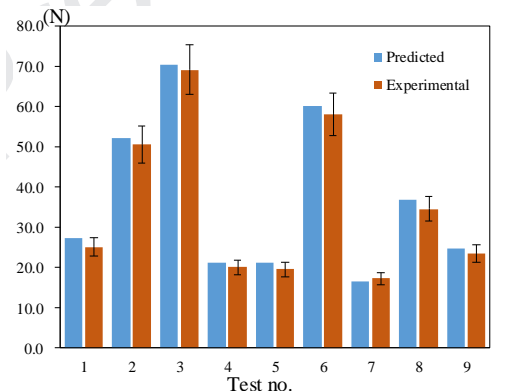

(b) Average axial cutting force

Fig. 7. Average cutting forces for different test group of cutting parameters.

\subsubsection{Comparison between predicted and experimental SCE}

As discussed above, the experimental SCE could be obtained as the ratio of net cutting power in experiments to MRR (i.e., $S C E=P_{\text {cutting }} / M R R$ ), and the net cutting power $P_{\text {cutting }}$ can be decomposed from the power curve monitored during machining experiments in accordance with the approach used in the literature (Yoon et al., 2014). Fig. 8 shows a decomposition example of the net cutting power using the measured power curve of test group 1 in whirling milling. The net cutting power $P_{\text {cutting }}$ can be calculated as the difference between normal power $P_{\text {normal }}$ during the normal cutting stage and the air cutting power $P_{\text {air }}$. Then, the experimental SCE can then be determined using the net cutting power $P_{\text {cutting }}$ and MRR under each test group of cutting parameters in Table 3. In addition, the method proposed by Satyarthi and Pandey (2013) was employed to validate the rightness of Eq. 7 for calculating MRR. Based on this method, the experimental MRR in $\mathrm{mm}^{3} / \mathrm{s}$ is calculated as the ratio of experimental MRR in $\mathrm{mg} / \mathrm{s}$ to the density 
1 (i.e., $7.81 \mathrm{mg} / \mathrm{mm}^{3}$ obtained by Table 1) of the workpiece material. The experimental MRR in

$2 \mathrm{mg} / \mathrm{s}$ is the rate of the removal weight of workpiece material that is obtained by weighting the

3 workpiece before and after cutting. The predicted MRR in $\mathrm{mm}^{3} / \mathrm{s}$ was calculated by Eq. (7), and

4 the comparison between the predicted and experimental MRR is presented in Table 4. It can be

5 observed that the maximum error in calculating the MRR is $2.1 \%$ for the 9 test groups.

7 Table 4

8 The comparison of the predicted and experimental MRR and specific cutting energy in whirling milling.

\begin{tabular}{llllllll}
\hline \multirow{2}{*}{ Test group no. } & \multicolumn{2}{l}{ MRR $\left(\mathrm{mm}^{3} / \mathrm{s}\right)$} & & \multicolumn{3}{l}{ Specific cutting energy $\left(\times 10^{-2} \mathrm{~J} / \mathrm{mm}^{3}\right)$} \\
\cline { 2 - 3 } & Predicted & Experimental & Error $(\%)$ & & Predicted & Experimental & Accuracy $(\%)$ \\
\hline 1 & 85.2 & 84.6 & 0.7 & & 135.3 & 130.0 & 96.0 \\
2 & 212.8 & 209.6 & 1.5 & & 115.9 & 110.5 & 95.2 \\
3 & 340.3 & 334.3 & 1.8 & & 112.1 & 117.2 & 95.7 \\
4 & 85.2 & 84.3 & 1.1 & & 151.9 & 139.7 & 91.3 \\
5 & 212.8 & 211.1 & 0.8 & & 153.9 & 141.6 & 91.3 \\
6 & 340.3 & 335.5 & 1.4 & & 113.9 & 107.3 & 93.8 \\
7 & 85.2 & 84.3 & 1.1 & & 221.0 & 204.5 & 91.9 \\
8 & 212.8 & 208.8 & 1.9 & & 123.2 & 117.4 & 95.0 \\
9 & 340.3 & 333.3 & 2.1 & & 139.1 & 127.3 & 90.7 \\
\hline
\end{tabular}

9

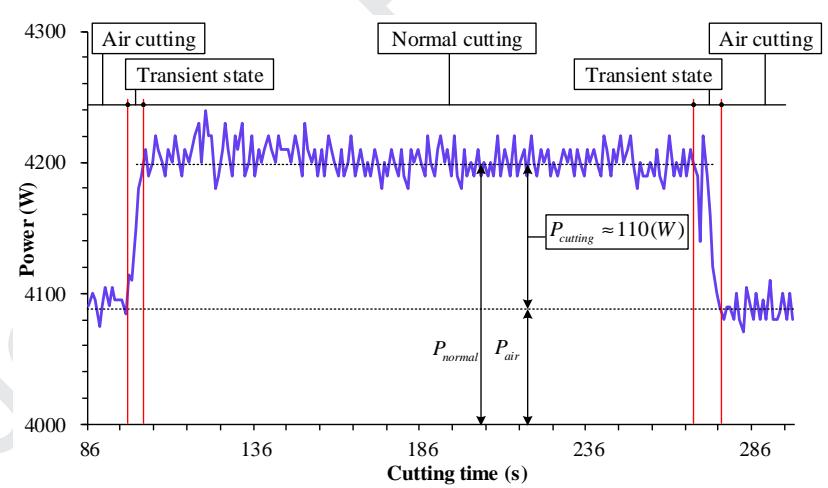

Fig. 8. Decomposition example of net cutting power $P_{\text {cutting }}$ test group 1 in the CNC whirling machine.

In order to validate the analytical model, the predicted SCE in whirling milling was obtained using the analytical model in Eq. (12b). The comparison between predicted and experimental SCE in Table 4 indicates that the prediction accuracy is greater than $90 \%$, which means that the proposed analytical model for whirling milling process can be employed for a reliable prediction of SCE under a given set of cutting conditions.

\section{Results and discussion}

In this section, after the model validation in Section 4, the SCE and MRR under different cutting parameter settings are calculated based on the validated analytical model (Eq. (12b)). The effects of both the cutting parameters on SCE and MRR and the effects of MRR on SCE was 
analyzed.

\subsection{Effects of cutting parameters on SCE and MRR}

The effects of cutting parameters on SCE are presented here, as shown in Fig. 9. In addition, according to the analysis in Section 2, the effects of cutting parameters on MRR (see Fig.8) are also required.

For the SCE, it can be found that it increases linearly with increasing cutting speed $n_{t}$, as shown in Fig. 9a. Fig. 9c shows a similar linear increasing variation of SCE with an increase in the number of cutting tools $Z$. By contrast, the nonlinear decreasing variations in SCE with workpiece speed $n_{w}$ and number of cutting tools $Z$ are shown in Fig. $9 \mathrm{~b}$ and d, respectively. The SCE decreased sharply with increasing $n_{w}$, as shown in Fig. 9b, but remained steady with increasing $R$, as shown in Fig. 9d. In particular, it is noted in Fig. 9b that the SCE decreased by more than a factor of three (i.e., from greater than $450 \times 10^{-2} \mathrm{~J} / \mathrm{mm}^{3}$ to less than $150 \times 10^{-2} \mathrm{~J} / \mathrm{mm}^{3}$ ) with the workpiece speed $n_{w}$ increasing from 0.5 to $5 \mathrm{rpm}$, and then remained approximately constant despite a further increase of $n_{w}$ from 5 to $10 \mathrm{rpm}$. This means that, when the workpiece speed $n_{w}$ was less than $5 \mathrm{rpm}$, it had a dominant effect on the SCE compared to $n_{t}, Z$, and $R$. In addition, it can be seen from Fig. 9 that the effects of $n_{t}, n_{w}, Z$, and $R$ were approximately the same order of magnitude for SCE when $n_{w} \geq 5 \mathrm{rpm}$.

For the MRR, it can be observed in Fig. 9a that the variation in MRR with increasing cutting speed $n_{t}$ was a horizontal line (i.e., constant value) for the different combinations of $n_{w}, Z$, and $R$. Similar results can be observed where the MRR remained constant despite the increasing number of cutting tools $Z$ and tool nose rotation radius $R$ in Fig. 9c and d, respectively. However, in Fig. 9b, compared to the effects of $n_{t}, Z$, and $R$ on MRR, it can be observed that MRR increased linearly with increasing workpiece speed $n_{w}$. This means that workpiece speed $n_{w}$ was the dominant cutting parameter affecting on MRR, while cutting speed $n_{w}$, number of cutting tools $Z$, and tool nose rotation radius $R$ had little effect. Therefore, the workpiece speed $n_{w}$ could be increased to improve MRR (i.e., cutting rate) and to further reduce the cutting time for energy saving.

The above results could be used for the optimal selection of cutting parameters, and could enable process planners and operators to select a low cutting speed $n_{t}$, small number of cutting tools $Z$, high workpiece speed $n_{w}$ (specifically $n_{w} \geq 5 \mathrm{rpm}$ ), or large tool nose rotation radius $R$ to reduce SCE and high workpiece speed $n_{w}$ to improve MRR. 


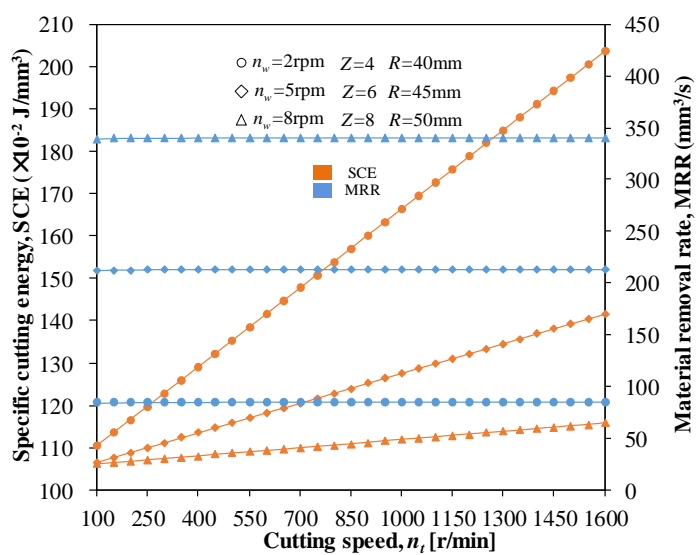

(a) The effect of cutting speed $\left(n_{t}\right)$

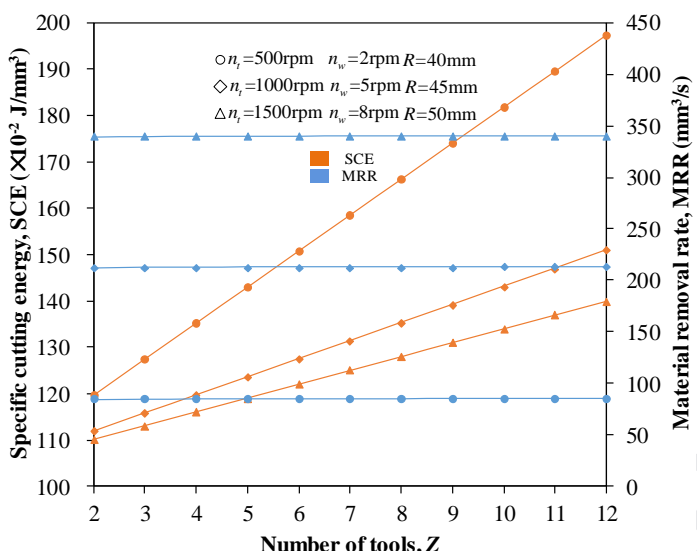

(c) The effect of number of tools $(Z)$

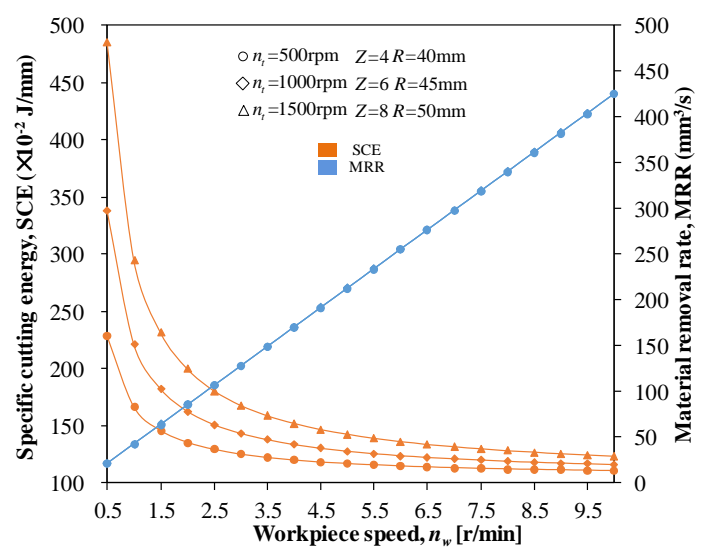

(b) The effect of workpiece speed $\left(n_{w}\right)$

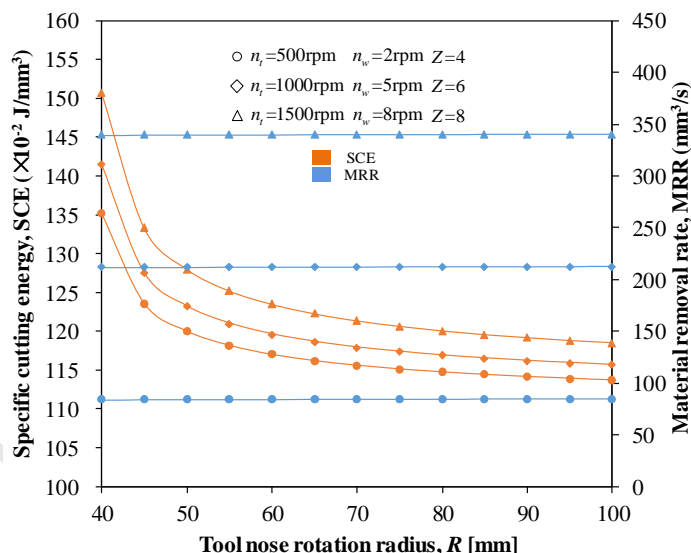

(d) The effect of tool nose rotation radius $(R)$

Fig. 9. The effects of cutting parameters on specific cutting energy and MRR.

\subsection{Effects of MRR on SCE}

As analyzed in Section 5.1, the workpiece speed $n_{w}$ was set as $5 \mathrm{rpm}$ (i.e., MRR $=212.8$ $\mathrm{mm}^{3} / \mathrm{s}$ ) and $8 \mathrm{rpm}$ (i.e., $340.3 \mathrm{~mm}^{3} / \mathrm{s}$ ). Fig. 10 shows the effects of MRR on SCE. The trends for SCE are shown in Fig. 10a, c, and e (MRR $\left.=212.8 \mathrm{~mm}^{3} / \mathrm{s}\right)$ and Fig. 10b, d, and $\mathrm{f}(\mathrm{MRR}=340.3$ $\left.\mathrm{mm}^{3} / \mathrm{s}\right)$.

It can be observed from Fig. 10a, c, and e that, with the MRR at $212.8 \mathrm{~mm}^{3} / \mathrm{s}$ in response to the varying number of cutting tools and the cutting speed, the SCE ranges varied from 105.8 to $143.9 \times 10^{-2} \mathrm{~J} / \mathrm{mm}^{3}, 106.3$ to $135.3 \times 10^{-2} \mathrm{~J} / \mathrm{mm}^{3}$, and 108.4 to $166.4 \times 10^{-2} \mathrm{~J} / \mathrm{mm}^{3}$, respectively. This means that SCE varied, even at the same MRR. Similar results can be observed where the SCE varied from 105.2 to $129.0 \times 10^{-2} \mathrm{~J} / \mathrm{mm}^{3}$ (Fig. 10b), 105.5 to $123.6 \times 10^{-2} \mathrm{~J} / \mathrm{mm}^{3}$ (Fig. 10d), and 106.8 to $143.0 \times 10^{-2} \mathrm{~J} / \mathrm{mm}^{3}$ (Fig. 10f) at the same MRR of $340.3 \mathrm{~mm}^{3} / \mathrm{s}$. Based on the abovementioned discussion, these results can contribute to reduce the SCE by selecting appropriate cutting parameters without impacting on the MRR (i.e., cutting rate). Fig. 10 also suggests that the optimal (minimal) SCE was $105.8 \times 10^{-2} \mathrm{~J} / \mathrm{mm}^{3}$ at an MRR of $212.8 \mathrm{~mm}^{3} / \mathrm{s}$, with cutting parameters $n_{t}=250 \mathrm{rpm}, n_{w}=5 \mathrm{rpm}, Z=2$, and $R=50 \mathrm{~mm}$, as in shown in Fig. 10a. 
1 Similarly, at an MRR of $340.3 \mathrm{~mm}^{3} / \mathrm{s}$, the optimal (minimal) SCE of $105.2 \times 10^{-2} \mathrm{~J} / \mathrm{mm}^{3}$ was

2 obtained under the cutting parameters $n_{t}=250 \mathrm{rpm}, n_{w}=8 \mathrm{rpm}, Z=2$, and $R=50 \mathrm{~mm}$, as

3 shown in Fig. 10b.

4 In addition, Fig. 10 also shows that the ranges of SCE varied from105.2 (see Fig. 10b) to 166.4 $5 \times 10^{-2} \mathrm{~J} / \mathrm{mm}^{3}$ (see Fig. 10e) with the variable MRR changing from 212.8 to $340.3 \mathrm{~mm}^{3} / \mathrm{s}$. From Fig.

610 , the SCE can be reduced by $61.2 \times 10^{-2} \mathrm{~J} / \mathrm{mm}^{3}$ and the MRR can be increased by $127.5 \mathrm{~mm}^{3} / \mathrm{s}$

7 by selecting the optimal of cutting parameters $n_{t}=250 \mathrm{rpm}, n_{w}=8 \mathrm{rpm}, Z=2$, and $R=50 \mathrm{~mm}$

8 (see Fig. 10b). Therefore, this implies that these results can be used for the optimization of the

9 process parameters for minimizing SCE as well as simultaneously improving MRR (i.e., cutting 10 rate).

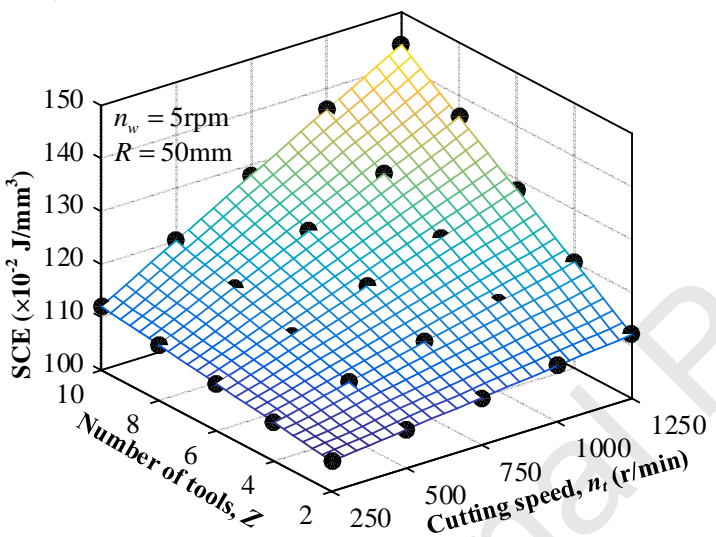

(a) $\mathrm{MRR}=212.8 \mathrm{~mm}^{3} / \mathrm{s}$

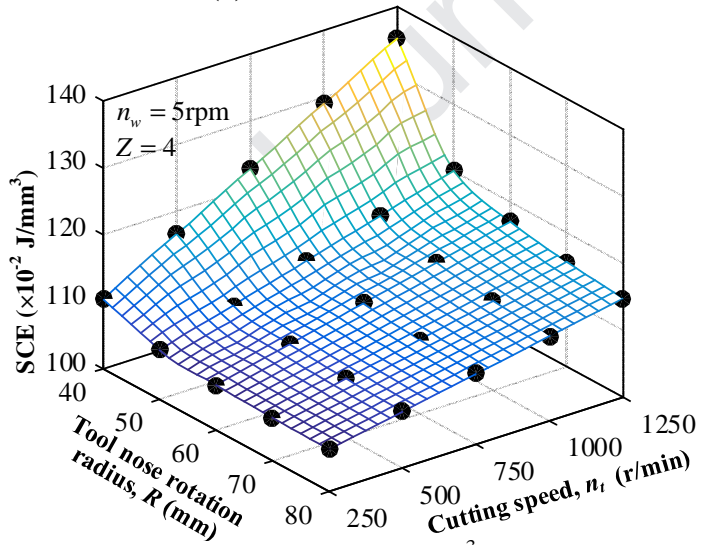

(c) $\mathrm{MRR}=212.8 \mathrm{~mm}^{3} / \mathrm{s}$

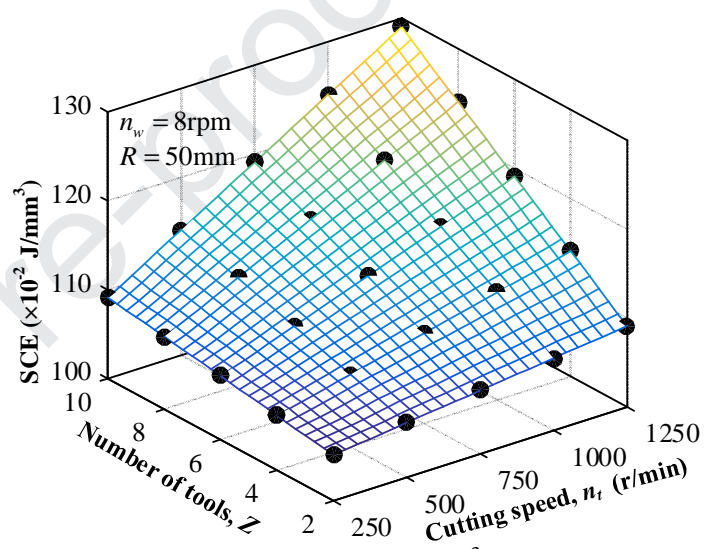

(b) $\mathrm{MRR}=340.3 \mathrm{~mm}^{3} / \mathrm{s}$

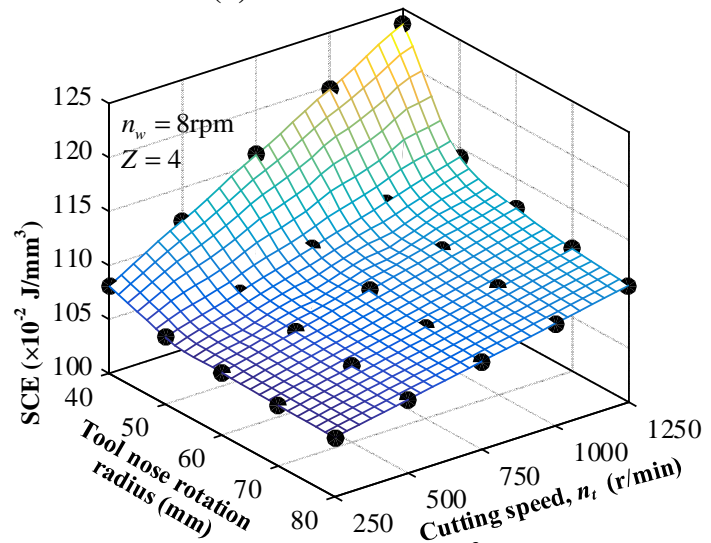

(d) $\mathrm{MRR}=340.3 \mathrm{~mm}^{3} / \mathrm{s}$ 


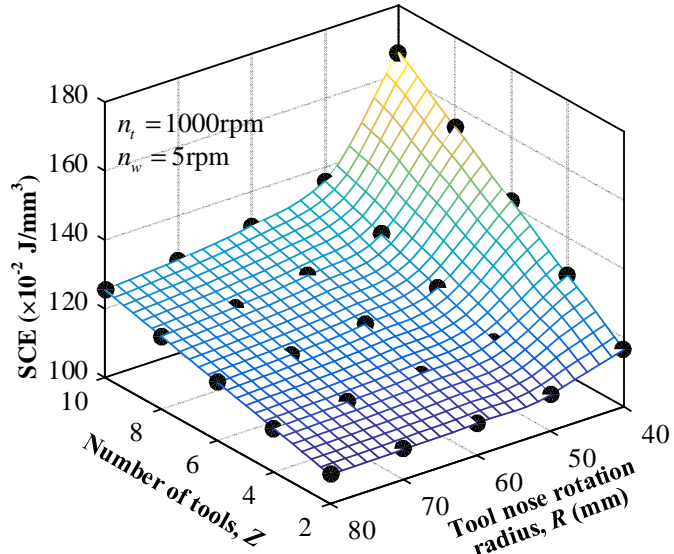

(e) $\mathrm{MRR}=212.8 \mathrm{~mm}^{3} / \mathrm{s}$

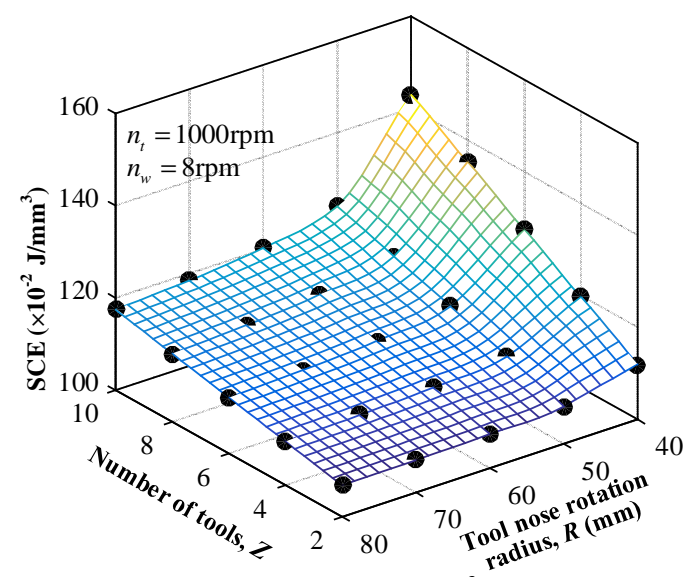

(f) $\mathrm{MRR}=340.3 \mathrm{~mm}^{3} / \mathrm{s}$

Fig. 10. Effects of MRR on specific cutting energy (SCE).

\section{Conclusions}

It has been approved that the SCE is significantly affected by cutting parameters and material removal mechanism within different machining processes. In previous studies, the SCE model in typical machining processes (e.g. turning and milling) was developed, and its variation under different cutting parameters was also analyzed. However, to date, the SCE of the whirling milling process has not been investigated because of the unique cutting parameters and material removal mechanism. This study proposed an analytical model for predicting SCE of the whirling milling process and investigated the understanding of the basic SCE characteristics and the variation in SCE under a wide range of cutting parameters and MRR. This study adds value for predicting the SCE and providing valuable information for the optimal selection of cutting parameters to reduce SCE, as well as to improve MRR for promoting energy efficiency and cutting rate in the promising whirling milling process, while machining precision transmission screw thread parts for modern advanced equipment. The primary conclusions drawn are as follows:

1. The SCE characteristics based on the material removal mechanism of whirling milling was investigated in detail. An analytical model for predicting SCE of the whirling milling process was developed as functions of cutting parameters.

2. The proposed analytical SCE model was implemented and validated in whirling milling a ball screw shaft on a CNC whirling machine. Comparison of the predicted and experimental SCEs indicated a prediction accuracy greater than $90 \%$, and the proposed model exhibited a satisfactory forecasting performance to predict the SCE of the whirling milling process for a given set of cutting parameters.

3. For the case study, this study indicated that a workpiece speed $n_{w}<5 \mathrm{rpm}$ had the greatest 
effect on the SCE of all cutting parameters. In addition, the effects of the four cutting parameters analyzed in this study were approximately of the same order of magnitude. It was suggested that a lower cutting speed $n_{t}$, smaller number of cutting tools $Z$, higher workpiece speed $n_{w}$, and higher tool nose rotation radius $R$ were beneficial for reducing the SCE of the whirling milling process. In particular, the workpiece speed $n_{w}$ should not be set less than $5 \mathrm{rpm}$ to reduce the SCE in ball screw shaft whirling milling.

4. The workpiece speed $n_{w}$ was the dominant parameter affecting the MRR of the whirling milling process, with the other parameters having a minimal effect. A high workpiece speed $n_{w}$ can be used to improve MRR (i.e., cutting rate), thereby reducing the cutting time for energy saving.

5. For the same MRR, the SCE of whirling milling process varied with the cutting parameters, which can be used to reduce the SCE without reducing the MRR.

6. The SCE and MRR of the whirling milling process could be optimized simultaneously by employing the proposed analytical model with the cutting parameters as the variables. For the case study, the SCE of the whirling milling could be reduced by $61.2 \times 10^{-2} \mathrm{~J} / \mathrm{mm}^{3}$ and, simultaneously, the MRR could be increased by $127.5 \mathrm{~mm}^{3} / \mathrm{s}$ by the suggested selection of optimal cutting parameters: $n_{t}=250 \mathrm{rpm}, n_{w}=8 \mathrm{rpm}, Z=2$, and $R=50 \mathrm{~mm}$.

\section{Acknowledgements}

The authors would like to thank the support from the National Natural Science Foundation of China (Grant No. 51575072), the Chongqing Research Program of Basic Research and Frontier Technology (No. cstc2015jcyjBX0088), the National Science and Technology Major Project of Ministry of Science and Technology of China (No. 2017ZX04019-001-003) and the Hanjiang Machine Tool Co., Ltd, China.

\section{References}

Altintas, Y., 2012. Manufacturing Automation: Metal Cutting Mechanics, Machine Tool Vibrations, and CNC Design, second ed. Cambridge University Press, Cambridge; New York.

Balogun, V.A., Heng, G., Mativenga, P.T., 2015. Improving the integrity of specific cutting energy coefficients for energy demand modelling. Proc. Inst. Mech. Eng. Part B-J. Eng. Manuf. 229, 2109-2117. https://doi.org/10.1177/0954405414546145.

Balogun, V.A., Mativenga, P.T., 2014. Impact of un-deformed chip thickness on specific energy in mechanical 
machining processes. J. Clean. Prod. 69, 260-268. https://doi.org/10.1016/j.jclepro.2014.01.036.

2

3

Bayoumi, A., Yücesan, G., Hutton, D., 1994. On the closed form mechanistic modeling of milling: specific cutting energy, torque, and power. J. Mater. Eng. Perform. 3, 151-158. https://doi.org/10.1007/BF02654511.

Cai, W., Liu, F., Dinolov, O., Xie, J., Liu, P.J., Tou, J.B., 2018. Energy benchmarking rules in machining systems. Energy 142, 258-263. https://doi.org/10.1016/j.energy.2017.10.030.

Camposeco-Negrete, C., 2013. Optimization of cutting parameters for minimizing energy consumption in turning of AISI 6061 T6 using Taguchi methodology and ANOVA. J. Clean. Prod. 53, 195-203. https://doi.org/10.1016/j.jclepro.2013.03.049.

Cui, X.B., Guo, J.X., 2018. Identification of the optimum cutting parameters in intermittent hard turning with specific cutting energy, damage equivalent stress, and surface roughness considered. Int. J. Adv. Manuf. Technol. 96, 4281-4293. https://doi.org/10.1007/s00170-018-1885-1.

Dahmus, J.B., Gutowski, T.G., 2004. An environmental analysis of machining. In: ASME 2004 International Machining Engineering Congress and RD\&D Exposition, Anaheim, CA, USA, pp. 13-19. https://doi.org/10.1115/IMECE2004-62600.

Fraunhofer, 2012. Eco Machine Tools Task 4 Report-Assessment of Base Case. Available on Online. http://www.ecomachinetools.eu/typo/reports.html?file=tl_files/pdf/EuP_Lot5_Task4_Aug2012.pdf_ (Last accessed September 2018).

Gao, S., Pang, S., Jiao, L., Yan, P., Luo, Z., Yi, J., Wang, X., 2017. Research on specific cutting energy and parameter optimization in micro-milling of heat-resistant stainless steel. Int. J. Adv. Manuf. Technol. 89, 191-205. https://doi.org/10.1007/s00170-016-9062-x.

Han, Q.Q., Liu, R.L., 2013. Theoretical model for CNC whirling of screw shafts using standard cutters. Int. J. Adv. Manuf. Technol. 69, 2437-2444. https://doi.org/10.1007/s00170-013-5214-4.

Lee, M.H., Kang, D.B., Son, S.M., Ahn, J.H., 2008. Investigation of cutting characteristics for worm machining on automatic lathe - Comparison of planetary milling and side milling. J. Mech. Sci. Technol. 22(12), 2454-2463. https://doi.org/10.1007/s12206-008-0713-1.

Li, Y.F., He, Y., Wang, Y., Wang, Y.L., Yan, P., Lin, S.L., 2015. A modeling method for hybrid energy behaviors in flexible machining systems. Energy 86, 164-174. https://doi.org/10.1016/j.energy.2015.03.121.

Liu, N., Wang, S.B., Zhang, Y.F., Lu, W.F., 2016a. A novel approach to predicting surface roughness based on specific cutting energy consumption when slot milling Al-7075. Int. J. Mech. Sci. 18, 13-20. https://doi.org/10.1016/j.ijmecsci.2016.09.002.

Liu, Z.Y., Guo, Y.B., Sealy, M.P., Liu, Z.Q., 2016b. Energy consumption and process sustainability of hard milling 
Liu, N., Zhang, Y.F., Lu, W.F., 2015. A hybrid approach to energy consumption modelling based on cutting power: a milling case. J. Clean. Prod. 104, 264-272. https://doi.org/10.1016/j.jclepro.2015.05.049.

Mohan, L.V., Shunmugam, M.S., 2007. Simulation of whirling process and tool profiling for machining of worms. J. Mater. Process. Tech. 185, 191-197. https://doi.org/10.1016/j.jmatprotec.2006.03.115.

Nandy, A.K., Gowrishankar, M.C., Paul, S., 2009. Some studies on high-pressure cooling in turning of Ti-6Al-4V. Int. J. Mach. Tools. Manuf. 49, 182-198. https://doi.org/10.1016/j.ijmachtools.2008.08.008.

Ni, S.Y., Li, Y., 2015. The measurement and prediction of cutting force for individual tooth in whirling process. J. Mech. Eng. 51(11), 207-212. https://dx.doi.org/10.3901/JME.2015.11.207.

Paul, S., Bandyopadhyay, P.P., Paul, S., 2017. Minimisation of specific cutting energy and back force in turning of AISI 1060 steel. Proc. Inst. Mech. Eng. Part B-J. Eng. Manuf. 232, 2019-2029. https://doi.org/10.1177/0954405416683431.

Pawade, R.S., Sonawane, H.A., Joshi, S.S., 2009. An analytical model to predict specific shear energy in high-speed turning of Inconel 718. Int. J. Mach. Tools Manuf. 49, 979-990. https://doi.org/10.1016/j.ijmachtools.2009.06.007.

Salahi, N., Jafari, M.A., 2016. Energy-performance as a driver for optimal production planning. Appl. Energy 174, 88-100. https://doi.org/10.1016/j.apenergy.2016.04.085.

Satyarthi, M.K., Pandey, P.M., 2013. Modeling of material removal rate in electric discharge grinding process. Int. J. Mach. Tools Manuf. 74, 65-73. https://doi.org/10.1016/j.ijmachtools.2013.07.008.

Sealy, M.P., Liu, Z.Y., Guo, Y.B., Liu, Z.Q., 2016a. Energy based process signature for surface integrity in hard milling. J. Mater. Process. Technol. 238, 284-289. https://doi.org/10.1016/j.jmatprotec.2016.07.038.

Sealy, M.P., Liu, Z.Y., Zhang, D., Guo, Y.B., Liu, Z.Q., 2016b. Energy consumption and modeling in precision hard milling. J. Clean. Prod. 135, 1591-1601. https://doi.org/10.1016/j.jclepro.2015.10.094.

Serizawa, M., Suzuki, M., Matsumura, T., 2015, Microthreading in Whirling. J. Micro. Nano-Manuf. 3, 41001-41007. https://doi.org/10.1115/1.4030704.

Son, J.H., Han, C.W., Kim, S.I., Jung, H.C., Lee, Y.M., 2010. Cutting forces analysis in whirling process. International Journal of Modern Physics $\quad$ B, 2786-2791. https://doi.org/10.1142/S0217979210065635.

Wang, B., Liu, Z.Q., Song, Q.H., Wan, Y., Shi, Z.Y., 2016. Proper selection of cutting parameters and cutting tool angle to lower the specific cutting energy during high speed machining of 7050-T7451 aluminum alloy. J. 
1 Clean. Prod. 129, 292-304. https://doi.org/10.1016/j.jclepro.2016.04.071.

2 Wang, Y.L., Li, L., Zhou, C.G., Guo, Q., Zhang, C.J., Feng, H.T., 2014. The dynamic modeling and vibration

3 analysis of the large-scale thread whirling system under high-speed hard cutting. Mach. Sci. Technol. 18(4),

4 522-546. https://doi.org/10.1080/10910344.2014.955366.

5 Yoon, H., Lee, J., Kim, M., Ahn, S., 2014. Empirical power-consumption model for material removal in three-axis 6 milling. J. Clean. Prod. 78, 54-62. https://doi.org/10.1016/j.jclepro.2014.03.061.

7 Zanger, F., Sellmeier, V., Klose, J., Bartkowiak, M., Schulze, V., 2017. Comparison of modeling methods to

8 determine cutting tool profile for conventional and synchronized whirling. Procedia CIRP 58, 222-227.

9 https://doi.org/10.1016/j.procir.2017.03.216. 


\section{Highlights}

- An analytical model for predicting specific cutting energy of whirling milling is proposed.

- Effects of cutting parameters and MRR on specific cutting energy of whirling milling are analyzed.

- The specific cutting energy characteristics based on material removal mechanism of whirling milling are investigated.

- The valuable information and guidance are obtained to minimize specific cutting energy and improve MRR. 